\title{
Effects of Hydrogen Addition on Design, Maintenance and Surveillance of Gas Networks
}

\author{
Pluvinage Guy ${ }^{1, *(\mathbb{D}}$, Toth Laszlo $^{2}$ and Capelle Julien ${ }^{1}$ (D) \\ 1 Laboratoire de Fiabilite Mecanique, Université de Lorraine, 57045 Moselle Metz, France; \\ julien.capelle@enim.univ-lorraine.fr \\ 2 Bay Zoltán Nonprofit Ltd. for Applied Research Engineering Division (BAY-ENG), Laszlo, Toth, \\ H-3519 Miskolc, Hungary; laszlo.toth@bayzoltan.hu \\ * Correspondence: pluvinage.guy@orange.fr
}

Citation: Guy, P.; Laszlo, T.; Julien, C. Effects of Hydrogen Addition on Design, Maintenance and Surveillance of Gas Networks. Processes 2021, 9, 1219. https:// doi.org/10.3390/pr9071219

Academic Editors: Giovanni Cinti, Shuk Han Chan and Arianna Baldinelli

Received: 21 April 2021

Accepted: 13 July 2021

Published: 15 July 2021

Publisher's Note: MDPI stays neutral with regard to jurisdictional claims in published maps and institutional affiliations.

Copyright: (c) 2021 by the authors. Licensee MDPI, Basel, Switzerland. This article is an open access article distributed under the terms and conditions of the Creative Commons Attribution (CC BY) license (https:/ / creativecommons.org/licenses/by/ $4.0 /)$.

\begin{abstract}
Hydrogen, when is blended with natural gas over time, degrades the materials used for pipe transport. Degradation is dependent on the proportion of hydrogen added to the natural gas. The assessment is made according to hydrogen permeation, risk to the integrity of structures, adaptation of surveillance and maintenance of equipment. The paper gives a survey of HE and its consequence on the design and maintenance. It is presented in a logical sequence: the design before use; the hydrogen embrittlement (HE) effects on Maximum Allowable Operating Pressure (MAOP); maintenance and surveillance during use of smooth and damaged pipes; and, particularly, for crack-like defects, corrosion defects and dents.
\end{abstract}

Keywords: hydrogen embrittlement; pipe steels; design; maintenance

\section{Introduction \\ 1.1. Hydrogen Economy}

An envisioned future predicts a large use of hydrogen for vehicle or heat fuel, energy storage, and energy transport [1]. The hydrogen economy would contribute to reducing green effect emissions and energy consumption. It stimulates economic growth and creates new jobs. However, the hydrogen economy also has to face technical challenges [2], competition with other technologies and interrelates with technology strategies. A sustainable energy carrier for electric vehicles is one of the future uses of hydrogen. It is also a medium for utility-scale renewable energy storage and fuel distribution. Because hydrogen can be produced from fossil, nuclear or renewable sources, dependence on imports and improvement of energy security can be reduced by promoting hydrogen.

It has several significant advantages:

- A large amount of energy is generated by combustion;

- It is very abundant on Earth;

- Its combustion is carbon free;

- It is storable and can be an efficient means of storing electricity over long periods of time.

However, hydrogen carrier still faces several limitations:

- A large amount of energy is necessary for storage of hydrogen in compressed liquid or metal hydride form;

- Transport is less efficient than that of oil or gas due to this low density when comparing energy transported per unit of volume;

- Risks of detonation and flammability with air;

- Production process cost, particularly water electrolysis, remains high;

- For hydrogen cars, the establishment of a network of hydrogen stations requires considerable time and investment. 


\subsection{Hydrogen Car}

The hydrogen car is considered as a "zero emission" vehicle [2]. It is also called "fuel cell electric vehicle", it runs on electricity like a conventional electric car. In hydrogen car, electricity is produced by a fuel cell (FC). This technic has several practical advantages.

Recharging takes less time than a full tank of gasoline, 3 to $5 \mathrm{~min}$, compared to the few hours to recharge a battery-powered car.

The range is similar to that of a diesel vehicle: a full tank of hydrogen in a 700-bar pressurized tank can travel up to $400 \mathrm{~km}$, two to three times more than battery-powered cars.

The FC is composed of several cells comprising two electrodes-an anode and a cathode-separated by a polymer membrane, which acts as an electrolyte. The electrochemical reactions between hydrogen injected at the anode and oxygen at the cathode lead to the production of electricity, heat and water. For this reason, FC is considered as a "clean" alternative to diesel and gasoline vehicles.

However, hydrogen car fuel cell suffers from the following disadvantages:

- The efficiency of the fuel cell is less than $50 \%$;

- The efficiency of the energy chain is, on average, 25 to $30 \%$ efficiency for a hydrogen car and around $70 \%$ for an electric one;

- With high-pressure tanks, pipes, fuel cell, buffer battery, and electronic power, it is a more complex car; therefore, the reliability level is lower;

- Expensive fuel cell, incorporating problematic resource potential (platinum);

- Service station development is heavier and more expensive than electric charging stations;

- Hydrogen is a very dangerous gas which can induce strong explosions in the event of a problem or leak;

- The use of high pressure in tanks needs to be checked and controlled.

\subsection{The Gas Mixture in End-Use Devices}

The transport of hydrogen into the existing gas pipeline network has been proposed to increase the use of renewable energy systems [3].

The injectable gas potential would be high enough to meet the demand. The injection of hydrogen in natural gas networks is called Power-to-Gas at a level less than $30 \%$.

There is a large variation between EU countries on maximum blend level of hydrogen in natural gas grid in the range $0-12 \%$, as seen in Figure 1.

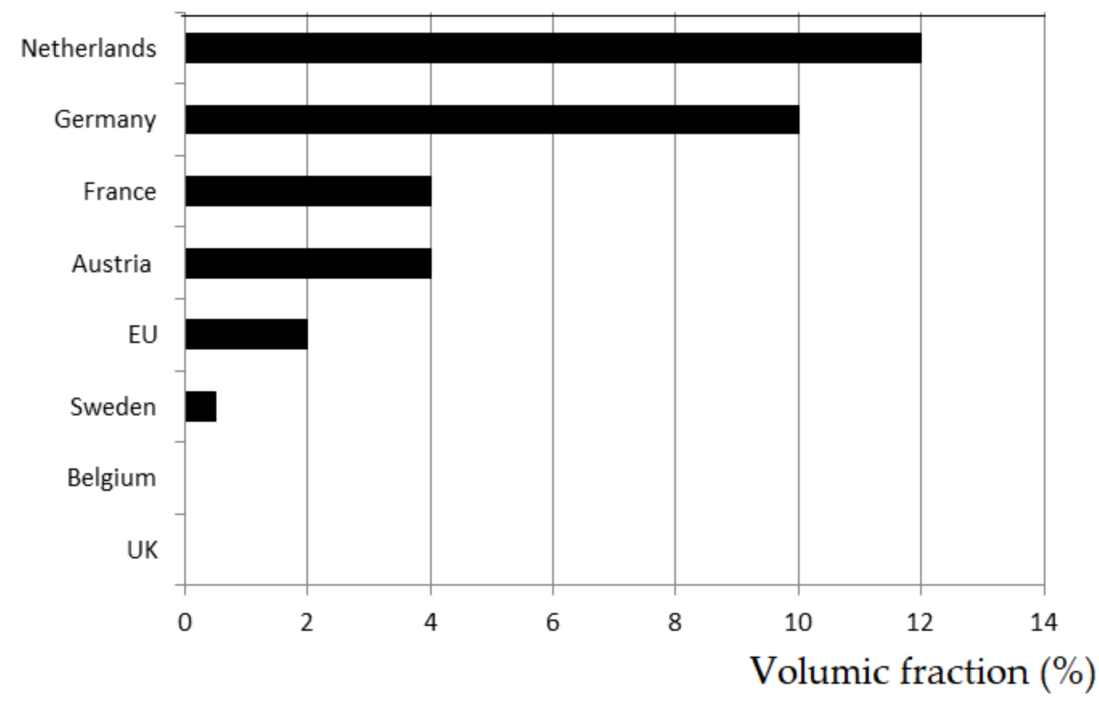

Figure 1. Variation between EU countries on maximum blend level of hydrogen in natural gas grid $(\%)$.

Adding hydrogen to natural gas links to the following problems: 
- Material-hydrogen compatibility: the material of pipe networks can be tolerant of the presence of hydrogen;

- The density, viscosity, flammability limits, etc., are modified. This has an impact on maintenance and surveillance of gas networks;

- Modification of the control of the gas combustion parameters.

In France, the GRHYD project [4], Figure 2, applies the concept of Power-to-Gas used to transform surplus renewable electricity into hydrogen via the electrolysis of water and, thus, allow storage and recovery.

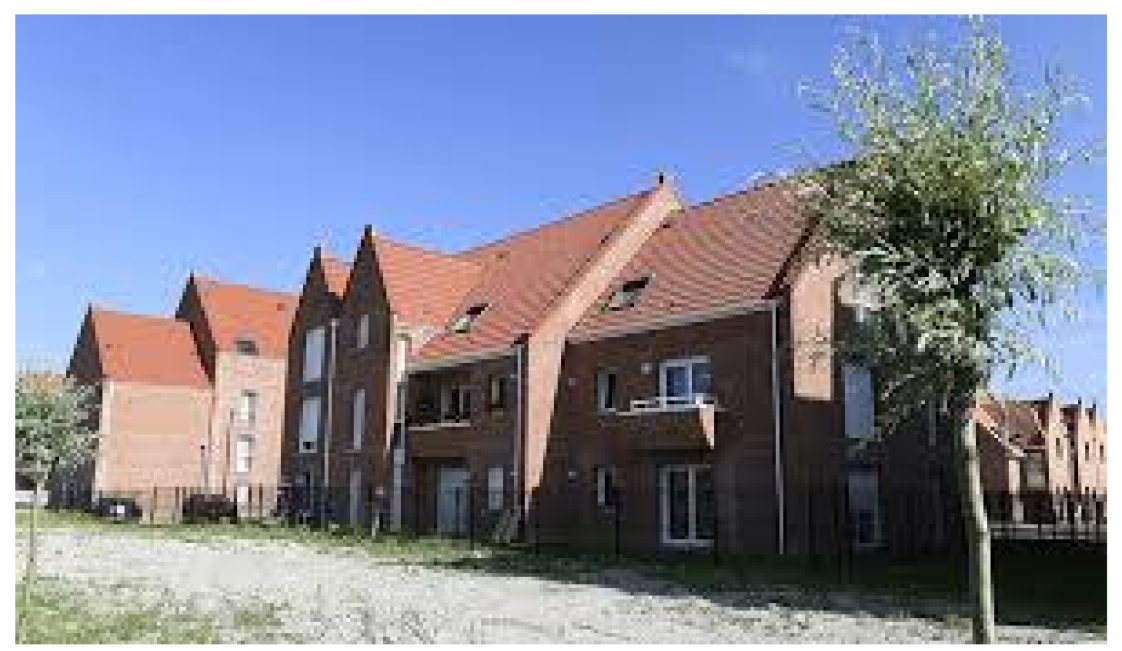

Figure 2. Natural gas network in district "petit village" at Capelle la Grande (France) with injection of hydrogen since June 2018 (https:/ / grhyd.fr), accessed on 5 April 2018.

The mixture of hydrogen and natural gas, in varying proportions of hydrogen not exceeding $20 \%$ by volume, supply the boiler room in the new district to meet the demand of about 100 homes.

Gas systems will have to be redesigned to allow the delivery and recovery of this energy on a large scale. The construction of new infrastructures or the adaptation of existing networks and equipment to the properties of the hydrogen molecule will be slow developments, which will require significant investment. The injection of hydrogen into current gas networks is, thus, seen as a solution to reduce the costs associated with the construction of new infrastructure, while guaranteeing an outlet to produce carbon-free hydrogen [5].

The addition of hydrogen in natural gas degrades over time the materials of transport and storage. This degradation depends on the ratio of hydrogen natural gas. After addition, several criteria need to be assessed:

- Hydrogen permeation through metals;

- Loss of pipe integrity;

- Adaptation of follow-up actions in service, surveillance, and maintenance of equipment.

In the following, the hydrogen embrittlement (HE) effect on design, maintenance and surveillance of smooth and damaged gas pipes is presented.

\section{Hydrogen Embrittlement}

It has been recognized since the end of the 19th century that hydrogen alters the steel mechanical properties [6] by hydrogen embrittlement (HE). To unlight this phenomenon, tensile tests on API L X52 pipe steel have been performed and presented in Figure 3. Specimens are loaded by an electrolytic process for $\mathrm{HE}$ and in air. One notes a reduction in failure elongation (38\%) and a small reduction in yield stress and ultimate strength, 
respectively, $3.8 \%$ and $7.4 \%$, as well as a reduction in fracture toughness. This phenomenon was first discovered by Johnson [6]. There was also a reduction in fracture resistance.

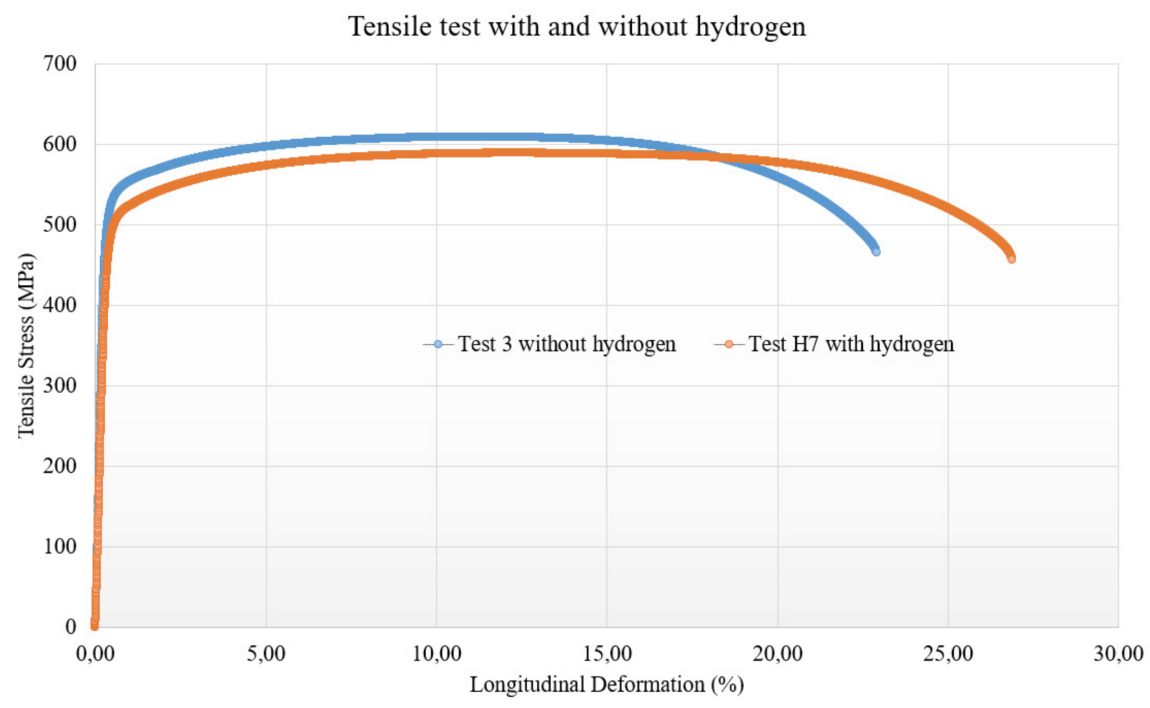

Figure 3. Stress-strain curves for API 5L X52 steel, the effect of HE.

Degradation of toughness increases the risk of gas line failure, loss of life, environmental damage, and economic loss associated with the repair of affected lines and loss of production.

Fracture initiation energy $U_{i}$ exhibits a sudden drop for hydrogen concentration higher than a critical one when the material becomes brittle, as noticed by Capelle et al. [7].

To understand the entry of hydrogen into metal, it is necessary to know the characteristics of the hydrogen evolution reaction and its distinct stages associated with the entire process. A double layer of hydrated atoms is transported on the surface. This hydrated form is separated in proton form and water and is adsorbed.

A discharge of the material is produced by electron donation. A combining hydrogen process occurs from atom to atom, atom to ion, or both. Finally, desorption and entry into the material results in the formation and diffusion of hydrogen.

Hydrogen moves easily between crystalline sites in steel; this is possible because it is small. It diffuses into metals by hetero-diffusion at infinite dilution. Trapping and accelerated transport atoms by mobile dislocations is the weakening mechanism. Dislocation rates are improved for perfect screw and wedge dislocations, partial dislocations, and grain boundary dislocations. The hydrogen atmosphere increases dislocation rate. This atmosphere protects interactions under elastic stress. This means that the separation distance between dislocations in a stack should collectively decrease.

The stack should approach the obstacle in the presence of hydrogen. A theoretical study has shown that hydrogen-induced softening and network expansion can cause shear localization in a material with a positive strain-hardening coefficient. Shear band bifurcation is a precursor to material failure. Hydrogen in metals accumulate in many locations. These locations are microstructures such as grain boundaries, inclusions, voids, dislocation tangles and dislocation networks, atoms in solute as well as in a solid solution. When hydrogen is fixed, failure will be controlled by the magnitude of the effects of hydrogen.

Hydrogen embrittlement is explained by several mechanisms, namely:

- Atomic bonds of metals weakening [8];

- Enhancement of plasticity;

- Emission of dislocations/decohesion competition [9];

- Molecular recombination in defects;

- Stress triaxiality. 
There is practically no effect of hydrogen embrittlement on yield stress and ultimate strength regardless of yield stress on pipe steels. The failure elongation ratio under influence of $\mathrm{HE}$ of several pipe steels versus yield stress is shown in Figure 4. The ratio $\left(\mathrm{A} \%\left(\mathrm{H}^{2}\right) / \mathrm{A} \%\right.$ (air)) decreases as the yield stress of the steel increases.

Elongation at failure $\mathrm{A} \%$

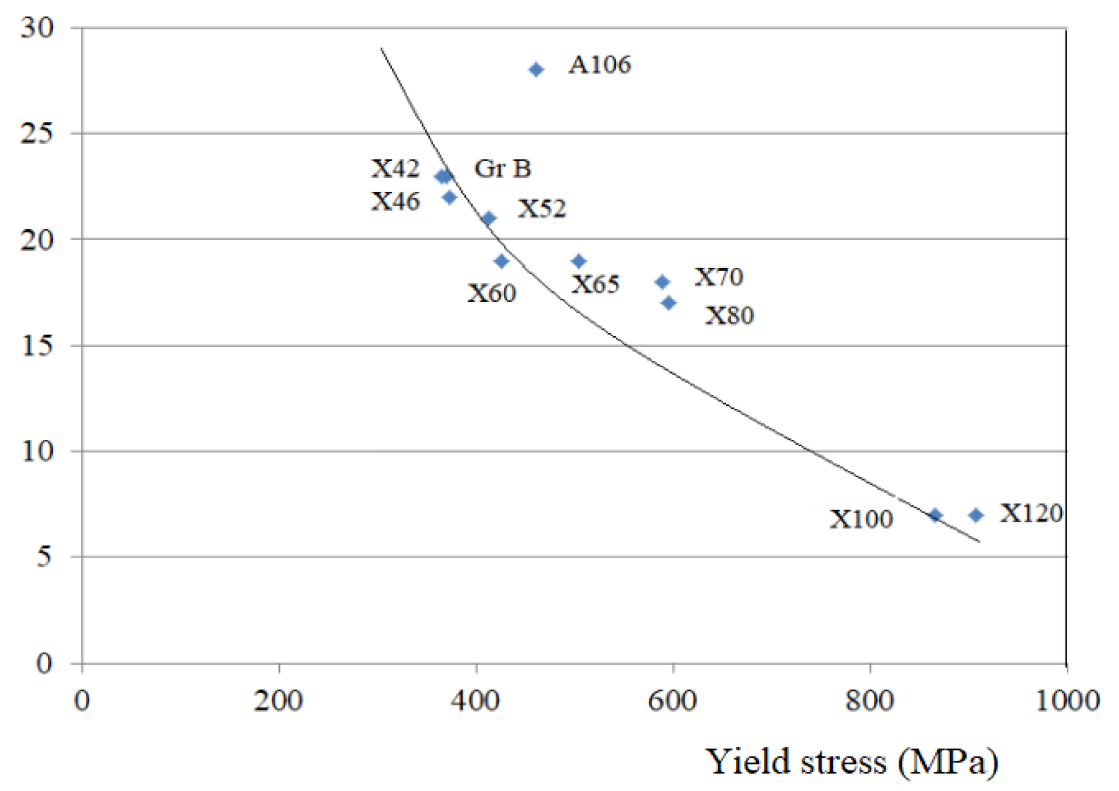

Figure 4. Failure elongation ratio of pipe steels after HE versus yield stress.

The fracture toughness is measured under conditions defined by standards. It is generally defined by the critical stress intensity factor $\mathrm{K}_{\mathrm{Ic}}$ whose units are the $\mathrm{MPa} \sqrt{ } \mathrm{m}$, the critical value of the energy parameter $J$ defines at initiation $\left(J_{c}\right)$ or, for a conventional value of stable crack propagation $\mathrm{J}_{0}$ whose units are $\mathrm{K}_{\mathrm{J}} / \mathrm{m}$, the critical value of COD (critical crack opening displacement $\delta_{c}$ ) whose units are millimeters.

By using the fracture toughness ratio under $\mathrm{HE}$ and without $\mathrm{HE}$, one can avoid the influence of the toughness determination method $\mathrm{K}_{\mathrm{IC}}, \mathrm{J}_{\mathrm{C}}$ or $\delta_{\mathrm{c}}$. Plotting versus yield strength shows a significant dispersion. Toughness decreases about $33 \%$ after HE, Figure 5.

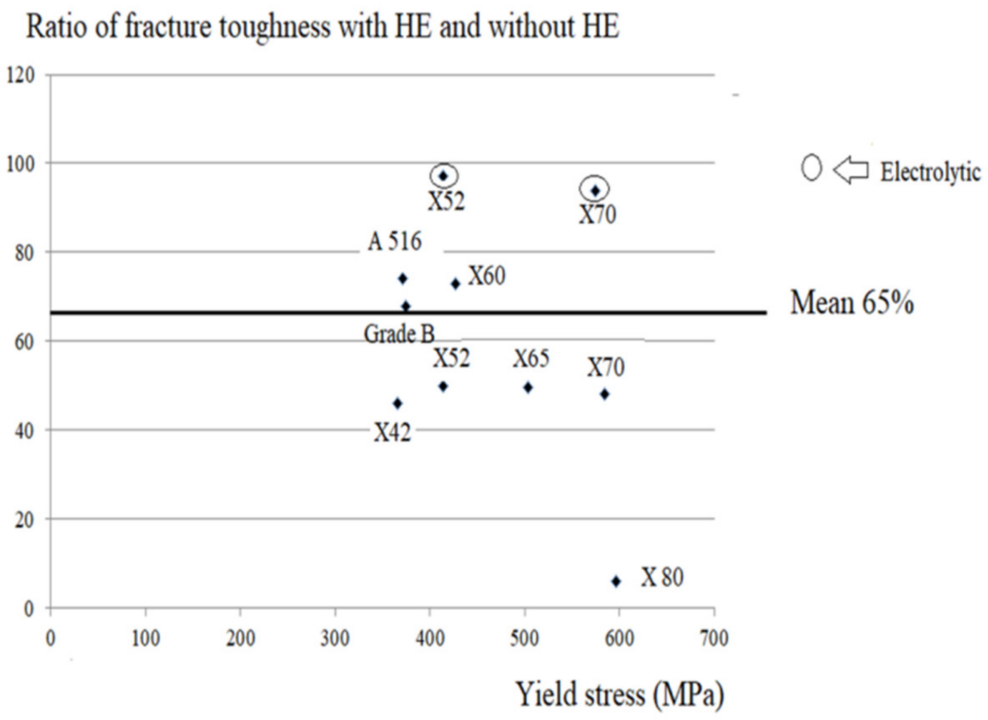

Figure 5. Evolution of fracture toughness ratio under the influence of HE for several pipe steels. 


\subsection{Fatigue Endurance}

Fatigue endurance after hydrogen embrittlement has received less attention in the literature than fatigue crack propagation. It is important to note that high cycle fatigue life is made up of 70 to $90 \%$ of life duration. Long cracks propagating in the domain of Paris Law after hydrogen embrittlement are mainly concerned.

Wöhler curves were drawn by [10] at both failure and initiation for API 5L X52 steel. The fatigue resistance at initiation curves is fitted by a power law:

$$
N_{i}=\sigma_{i}^{\prime}(\Delta \sigma)^{\beta}
$$

$\sigma_{i}^{\prime}$ is the fatigue initiation resistance, $N_{i}$ fatigue initiation numbers. Figure 6 presents the $N_{i} / N_{r}$ ratio versus the number of cycles to failure $N_{r}$. Values for API X52 pipe sttel are given in Table 1.

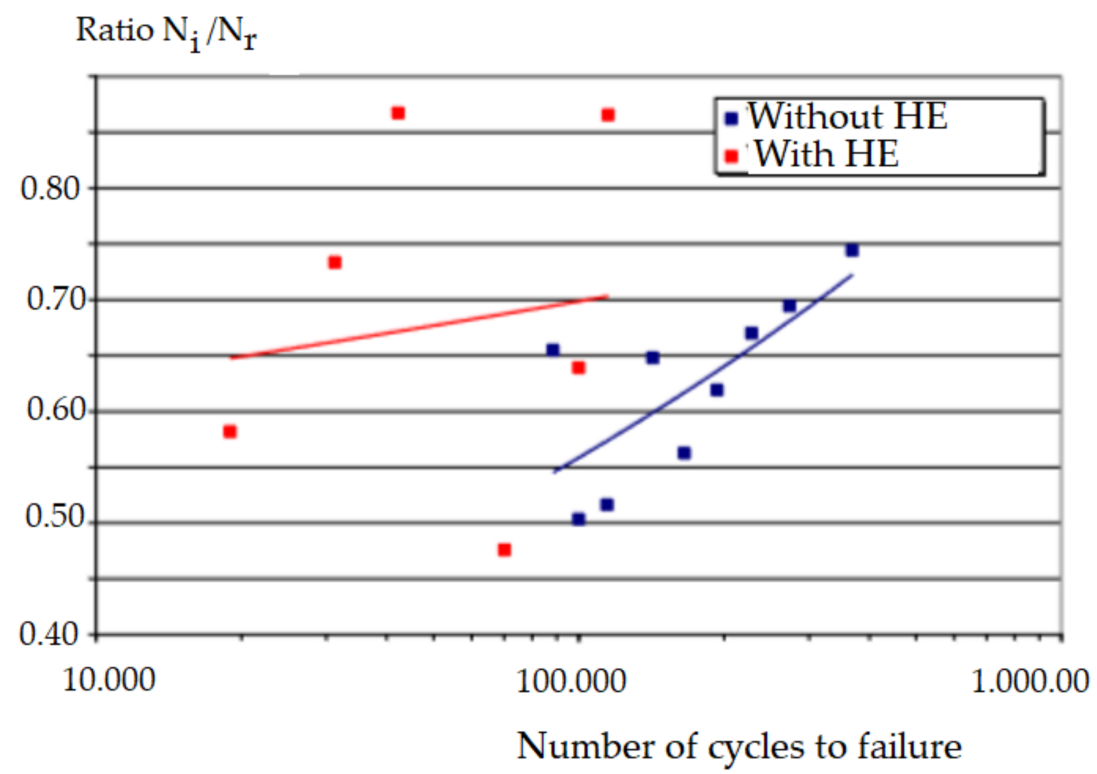

Figure 6. $N_{i} / N_{r}$ ratio versus the number of failure cycles for API 5L X52 steel [11].

Table 1. Fatigue initiation resistance and exponent $\beta$ for API 5L X52 steel [11].

\begin{tabular}{cccc}
\hline & $\begin{array}{c}\text { Fatigue Initiation } \\
\text { Resistance } \sigma_{i}^{\prime} \\
(\mathbf{M P a})\end{array}$ & Exponent $\boldsymbol{\beta}$ & $\mathbf{R}^{\mathbf{2}}$ \\
\hline Air & 336.05 & -0.0202 & 0.8843 \\
Hydrogen & 301.14 & -0.0121 & 0.9502 \\
\hline
\end{tabular}

Fatigue crack propagation is faster after HE and the $N_{r}-N_{i}$ difference is reduced. $N_{r}-N_{i}$ is precisely the number of propagation cycles. The $N_{i} / N_{r}$ ratio suffers from a large scatter.

\subsection{Fatigue Crack Propagation}

Hydrogen embrittlement affects fatigue crack propagation in stage II (Paris law regime) and particularly carbon pipe steels. Crack growth rate versus the maximum amplitude of the stress intensity factor in natural gas is presented in Figure 7 by the solid line curve. 


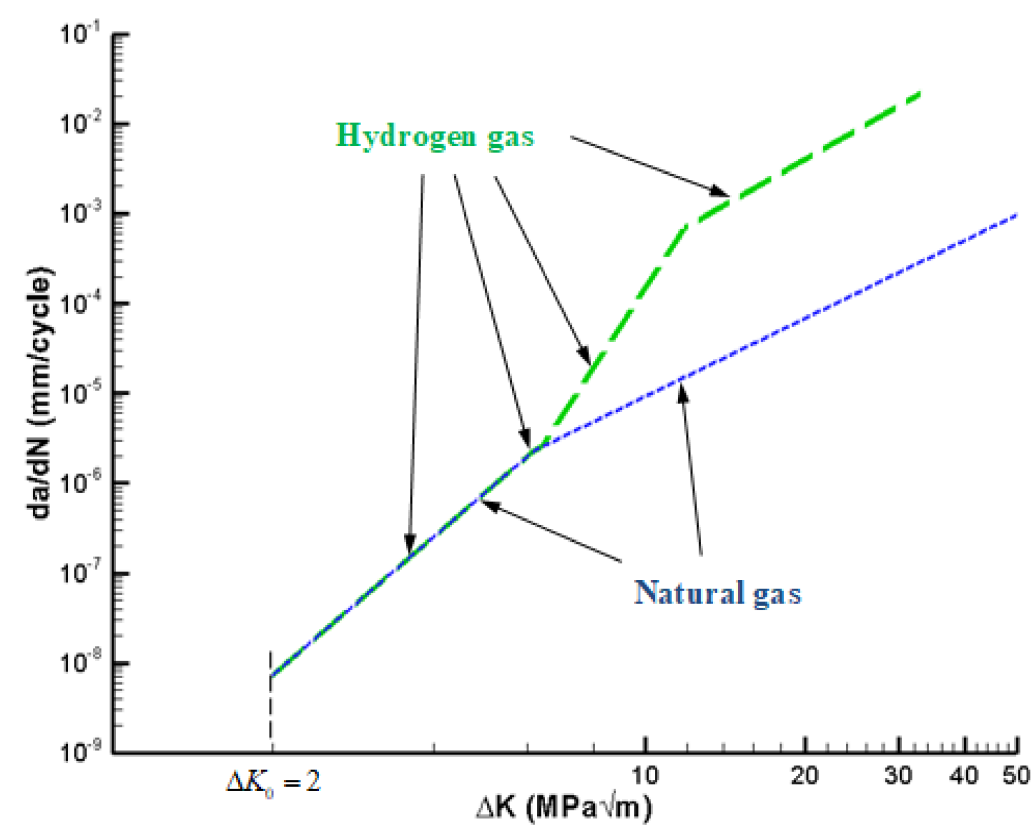

Figure 7. Diagram of the crack growth curve as a function of the stress intensity factor range $\Delta \mathrm{K}$ for natural gas (blue curve) and for hydrogen, (green curve).

The process is made up of three stages:

- In the beginning, the growth rate increases along the sigmoidal curve governed by the fatigue crack threshold $\mathrm{K}_{\mathrm{TH}}$, step 1 . An increase in fatigue crack growth is attributed to hydrogen diffusion at the crack tip.

The growth rate is faster than the hydrogen diffusion rate with a low local concentration of hydrogen at the crack tip. At the start of step 2, the growth rate decreases. An equilibrium between the rate of growth of the crack and the rate of diffusion of hydrogen is achieved later. A plateau is obtained, and the crack growth rate remains constant. The equilibrium state is ensured by continuous hydrogen charging and crack growth.

Stage 3 begins when the crack growth resistance given by the toughness after $\mathrm{HE} \mathrm{K}_{\mathrm{IC}}$ $\mathrm{H}$ is less than intrinsic fracture toughness $\mathrm{K}_{\mathrm{IC}}$. The fatigue growth rate curve is governed only by $\mathrm{K}_{\mathrm{TH}}$ and $\mathrm{K}_{\mathrm{IC}, \mathrm{H}}$; both are drawn using dotted lines. The rate of fatigue crack growth is greatly increased - one to two orders of magnitude-by hydrogen embrittlement in the Paris law domain. Under hydrogen, the exponent of the Paris law increases strongly in the stress intensity factor range $\Delta \mathrm{K}$ range [6-12 $\mathrm{MPa} \sqrt{ } \mathrm{m}]$. Beyond that, it finds the same value as that of the law of growth of fatigue crack in air. According to [12], the crack growth rate increases strongly for low frequencies and presents a plateau for a frequency lower than $1 \mathrm{~Hz}$, Figure 8. 


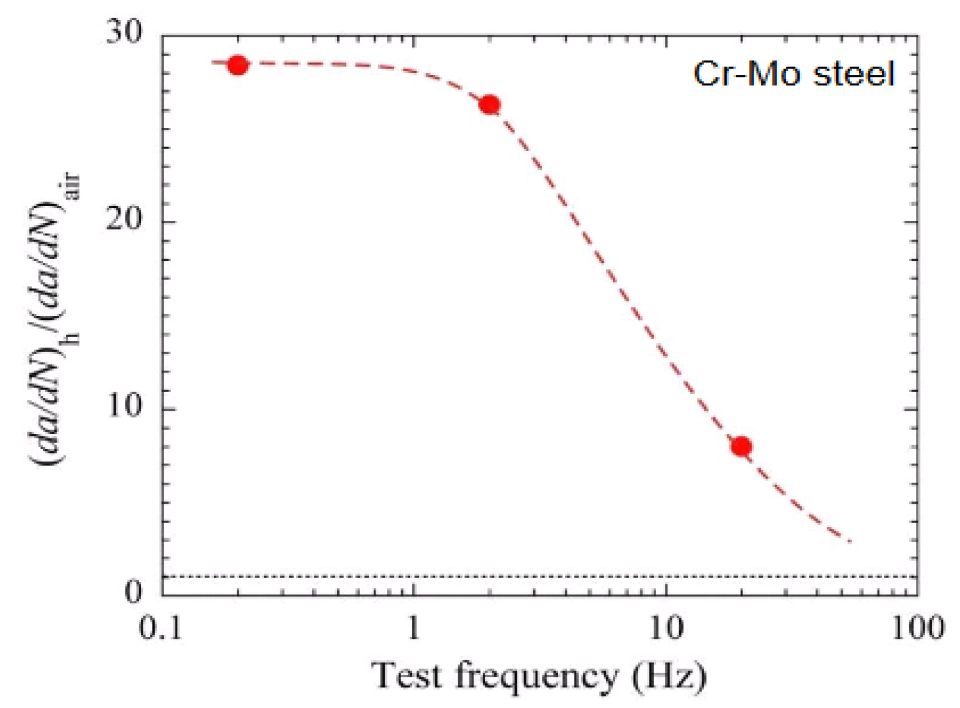

Figure 8. Influence of frequency on the crack growth rate, hydrogen tests [12].

\section{Design against Brittle Fracture}

Brittle fracture is taken into account in design by ensuring that the material must have a ductile behavior at service temperature. Therefore, ductility is sufficient to prevent cleavage triggering with a significant release of elastic energy. This concept concerns level I in several codes like API 579-1 ASME FFS-1 at [13]. For that, the service temperature $T_{s}$ is higher than the brittle-ductile transition temperature [DBTT) $\mathrm{T}_{t}$. Codes or laws define the service temperature conventionally according to the country where the structure or component is constructed or installed.

In France, the service temperature is $-20^{\circ} \mathrm{C}$. When this concept is based on fracture mechanics, designers ensure that the service temperature $T_{S}$ is greater than fracture toughness transition temperature $\mathrm{T}_{0}$.

$\mathrm{T}_{0}$ corresponds to a conventional fracture toughness value of $\mathrm{K}_{\mathrm{Ic}, \mathrm{ad}}=100 \mathrm{MPa} \sqrt{ } \mathrm{m}$ on the curve fracture toughness- temperature. More generally, reference temperature (RT), must be greater than service temperature:

$$
\mathrm{T}_{\mathrm{s}} \geq \mathrm{RT}+\mathrm{T}
$$

$\Delta \mathrm{T}$ is the uncertainty [13].

The reference temperature is generally given by the designer or the codes to have a transition temperature close to those of the "structure or component". Transition temperatures are specific to tests. The level of conservatism in the design depends on this choice. Transition temperature is sensitive to constrain according to [14]. It decreases when they constrain due to thickness, triaxiality or loading mode decreases. A test providing a constrain value close to that of the structure minimizes the conservatism. It should be noted that the choice of Charpy test piece is highly conservative due to the high constrain specimen because the bending test with high triaxiality induces via sharp $V$ notch.

For thin pipes, standard, Charpy test specimens of $10 \mathrm{~mm}$ thickness cannot be extracted. In this case, mini Charpy test are preferred. Experimental results are fitted according to a hyperbolic tangent law (Oldfield) [15].

$$
\mathrm{K}_{\mathrm{cv}}=\mathrm{A}_{\mathrm{cv}}+\mathrm{B}_{\mathrm{cv}} \tanh \left[\frac{\left(\mathrm{T}-\mathrm{D}_{\mathrm{cv}}\right)}{\mathrm{C}_{\mathrm{cv}}}\right]
$$

Constants $A_{C V}, B_{C V}, C_{C V}$ are related to energy level of the ductile plateau USE, energy level at brittle plateau LES, DBTT is the ductile-brittle transition temperature. 


$$
\begin{gathered}
\mathrm{A}_{\mathrm{CV}}+\mathrm{B}_{\mathrm{CV}}=\mathrm{USE} \\
\mathrm{A}_{\mathrm{CV}}-\mathrm{B}_{\mathrm{CV}}=\mathrm{LES} \\
\mathrm{D}_{\mathrm{CV}}=\mathrm{DBTT}
\end{gathered}
$$

For pipe steel API $5 \mathrm{~L}$ X60, the mini-Charpy energy-temperature curve is presented in Figure 9. Data are fitted according to Equation (3). $\mathrm{A}_{\mathrm{CV}}, \mathrm{B}_{\mathrm{CV}}, \mathrm{C}_{\mathrm{CV}}$ and, $\mathrm{D}_{\mathrm{cv}}$ are reported in Table 2.

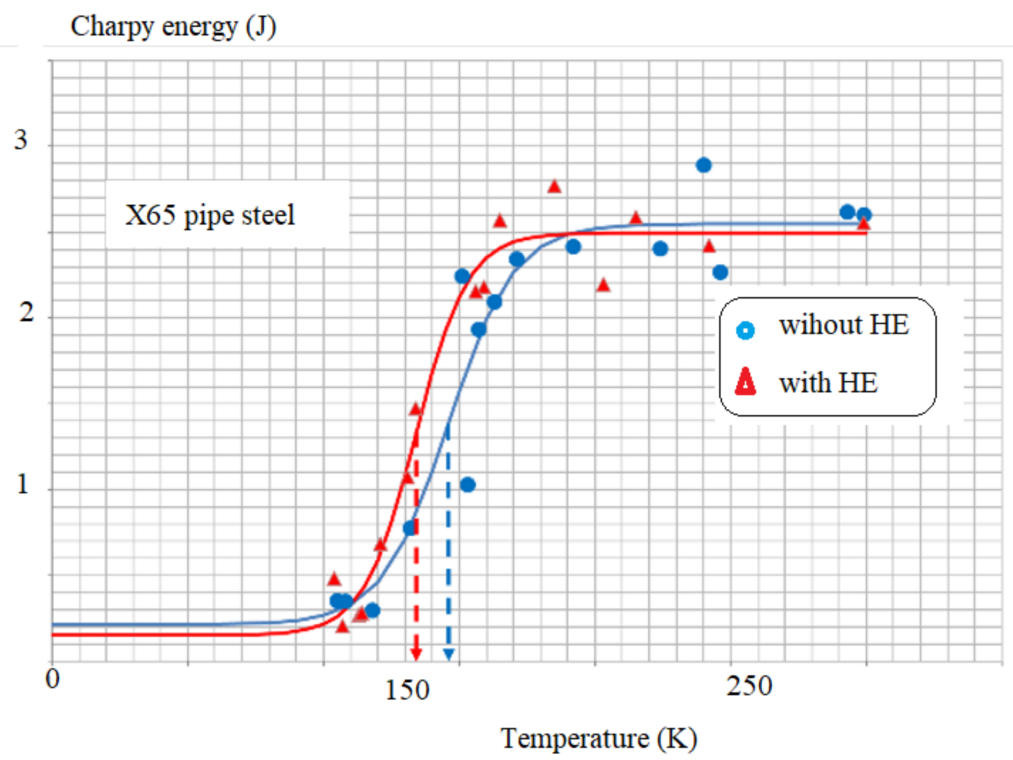

Figure 9. Charpy energy-temperature curves for tests performed on mini Charpy specimens made in X65 steel with and without hydrogen embrittlement.

Table 2. Values of constants of Equation (3).

\begin{tabular}{ccccc}
\hline & $\mathbf{A}_{\mathbf{c v}}(\mathbf{J})$ & $\mathbf{B}_{\mathbf{c v}}(\mathbf{J})$ & $\mathbf{C}_{\mathbf{c v}}(\mathbf{K})$ & $\mathbf{D}_{\mathbf{c v}}(\mathbf{K})$ \\
\hline $\mathrm{H}^{2}$ & 1.5 & 1.05 & 8.0 & 166 \\
\hline Air & 1.6 & 0.95 & 8.2 & 156 \\
\hline
\end{tabular}

The Charpy energy-temperature curve exhibits a slightly different behavior from that obtained with the material without HE. The brittle and ductile plateau levels are similar, but the transition temperature define by $\mathrm{D}_{\mathrm{CV}}$ is increased from $10{ }^{\circ} \mathrm{C}$, i.e., very few. The authors of [16], performing tests on Standard Charpy specimens, also made of X65 pipe steel, noted no shift in transition temperature defined at the energy level of 27 joules.

\section{Design Factor for Smooth Pipe Transporting Hydrogen Blended with Natural Gas}

When the service pressure $p_{s}$ exceeds the Maximum Admissible Operating Pressure (MAOP), the leak is considered to happen on smooth pipes.

$$
\mathrm{p}_{\mathrm{s}} \geq \mathrm{MAOP}
$$

The calculation formula of ASME code [1] involves partial safety coefficients. Reduction in thickness has to be considered.

$$
\mathrm{MAOP}=\frac{2 \mathrm{Se}_{\mathrm{e}}}{\mathrm{D}} \mathrm{f}_{0} \mathrm{ETH}_{\mathrm{f}}
$$

e: nominal thickness; 
$\mathrm{f}_{0}$ : design factor;

D: nominal outside diameter;

E: Weld factor;

$\mathrm{H}_{\mathrm{f}}$ : Material performance factor;

$\mathrm{S}$ : specified minimum yield strength;

$\mathrm{T}$ : Temperature derating factor.

The specified minimum yield strength $S$ is given from pipe steel designation, for example, API $5 \mathrm{~L} X\left(\sigma_{\mathrm{y}, \text { specif }}\right)$ as

$$
\mathrm{S}=\sigma_{\mathrm{y}, \text { specif }} * \mathrm{f}_{0}
$$

The maximum admissible stress $\sigma_{a d}$ is given by the following formula:

$$
\sigma_{a d}=\sigma_{\mathrm{y}, \text { ref. }} \mathrm{f}_{0}
$$

where $\sigma_{\mathrm{y}}$, ref is the material reference yield stress and $\mathrm{f}_{0}$ is the design factor.

Values of design factor for the natural gas grid are given by code [17] in France. Value depends on pipe localization as can be seen in Table 3.

Table 3. Design factor for natural gas pipe [17].

\begin{tabular}{cccc}
\hline & Urban & Semi-Urban & Country \\
\hline $\mathrm{f}_{0}$ & 0.4 & 0.6 & 0.73 \\
\hline
\end{tabular}

The yield stress of pipes steel is not affected by hydrogen embrittlement—see Figure 10. However, this only consideration leads to the same design factor being kept for the same admissible stress for hydrogen embrittlement. However, hydrogen transport needs to also consider the risk of explosion due to the large inflammability range and low ignition energy. For transport of hydrogen in pipes, other design factors $\mathrm{f}_{0}$ have been chosen by American code ASME B31.12-2004 [18] with respect to pipeline location, as indicated in Table 4.

Ratio Hydrogen/natural gas

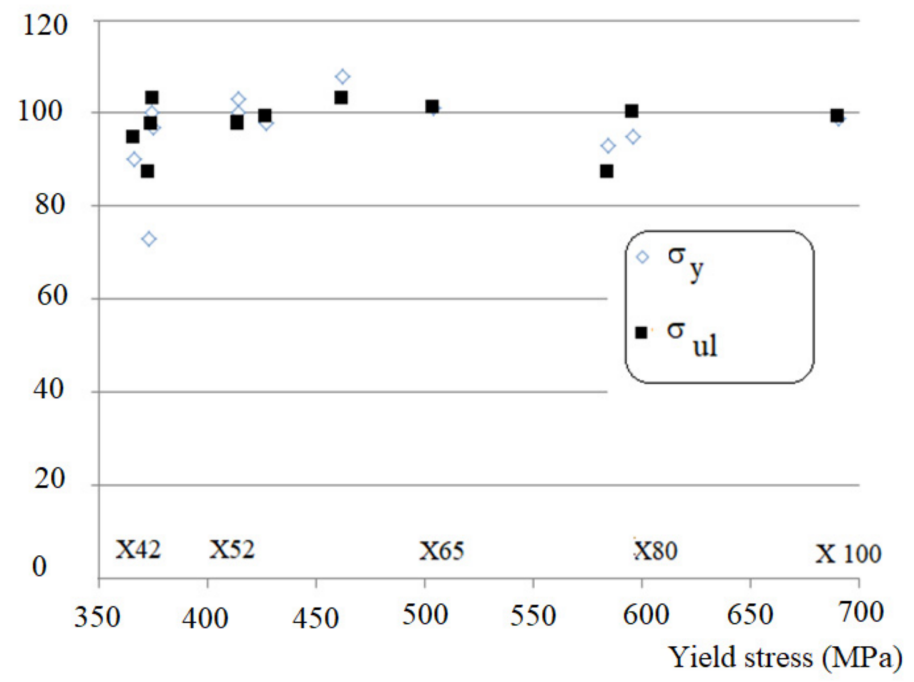

Figure 10. Ratio of yield stress and ultimate strength ratios with and without hydrogen embrittlement versus yield stress.

Table 4. Design factor for pipes transporting hydrogen [18].

\begin{tabular}{ccccc}
\hline Class & $\mathbf{1}$ & $\mathbf{2}$ & $\mathbf{3}$ & $\mathbf{4}$ \\
\hline Design factor, $\mathrm{f}_{0}$ & 0.72 & 0.6 & 0.5 & 0.4 \\
\hline
\end{tabular}


Four cases have been defined for code division 2 (high constraint environment)

- Class 1 (corresponds to an environment with high constraint);

- Class 2 (corresponds to a rural environment);

- Class 3 (corresponds to a peri-urban environment);

- Class 4 (corresponds to a highly urbanized environment).

According to the pipe steel and service pressure, the design factor is used for the determination of pipe diameter.

Based on expert judgments, the design factor is a deterministic factor. New trends are based on a probabilistic approach. The following general equation is use for calculated the risk associated with pipeline transport:

Risk $=$ Frequency of pipeline failure $\times$ Probability of ignition $\times$ Human, economic or societal consequences.

Codes consider an individual and human risk, i.e., the probability for a given pipeline length, that a person will become a victim in a year. Global risk is the product of all failures and consequences (per year). The risk is given by the probability that a point located near a pipe and at a known distance could be exposed to an effect of an intensity greater than a reference level. This probability is expressed by:

$$
\operatorname{Pr}_{r}(\text { Risk })=\operatorname{Pr}(F){ }^{*} \mathrm{Crr}{ }^{*} \operatorname{Pr}(Q) * \operatorname{Pr}(I) * \operatorname{Pr}(E F) L{ }^{*} \mathrm{Cev} * \operatorname{Pr}(\text { pers })
$$

where:

$P_{r}(F)$ leak probability after failure;

$P_{r}(Q)$ probability of flow greater than a critical value;

$P_{r}(I)$ probability of ignition;

$P_{r}(E F)$ probability of lethal effects greater than a threshold value;

$P_{r}$ (pers) probability of the presence of a person;

$L$ length of the pipeline;

$C_{e v}$ coefficient to consider the environment of the pipeline;

$C_{r r}$ risk reduction factor considering risk reduction measures.

If $P_{r}$ (Risk) is distributed according to a simple Weibull law. The safety factor is defined as:

$$
f_{s}=\frac{\Gamma_{a}\left(1+1 / m_{W}\right)}{\left[\operatorname{Ln}\left(1 / P_{s}\right)\right]^{1 / m_{W}}}
$$

where $m$ is the Weibull exponent. Table 5 presents a comparison between probabilistic design factor $\mathrm{f}_{0 \text {,prob }}$ (present method) [18] and deterministic one $\mathrm{f}_{0, \text { det }}$ [17]. Deterministic values differ between the three locations and are more conservative. In [17], no description of arguments that leads to values of deterministic design factor is presented.

Table 5. Probabilistic design factor $\mathrm{f}_{0 \text {, prob }}$ and, deterministic design factor $\mathrm{f}_{0 \text {, det. }}$

\begin{tabular}{cccc}
\hline & Rural Area & Peri-Urban Area & Urban Area \\
\hline $\mathrm{f}_{0 \text {, prob }}$ & 0.8 & 0.7 & 0.7 \\
\hline $\mathrm{f}_{0, \mathrm{det}}$ & 0.6 & 0.5 & 0.4 \\
\hline
\end{tabular}

This is valid only for pipe geometry and steel API 5L X60. A larger study on other pipe geometry and steels could not strongly modify the conclusion.

The coefficient of variation (COV) of the steel yield stress is incorporated in Equation (9). Therefore, the design factor is sensitive to the COV of material properties. Figure 11 presents the influence of yield stress COV on MAOP. This figure indicates that, for an urban area, the MAOP decreases by $90 \%$ and the design factor by $85 \%$ when COV vary in the range [0.05-0.20]. 


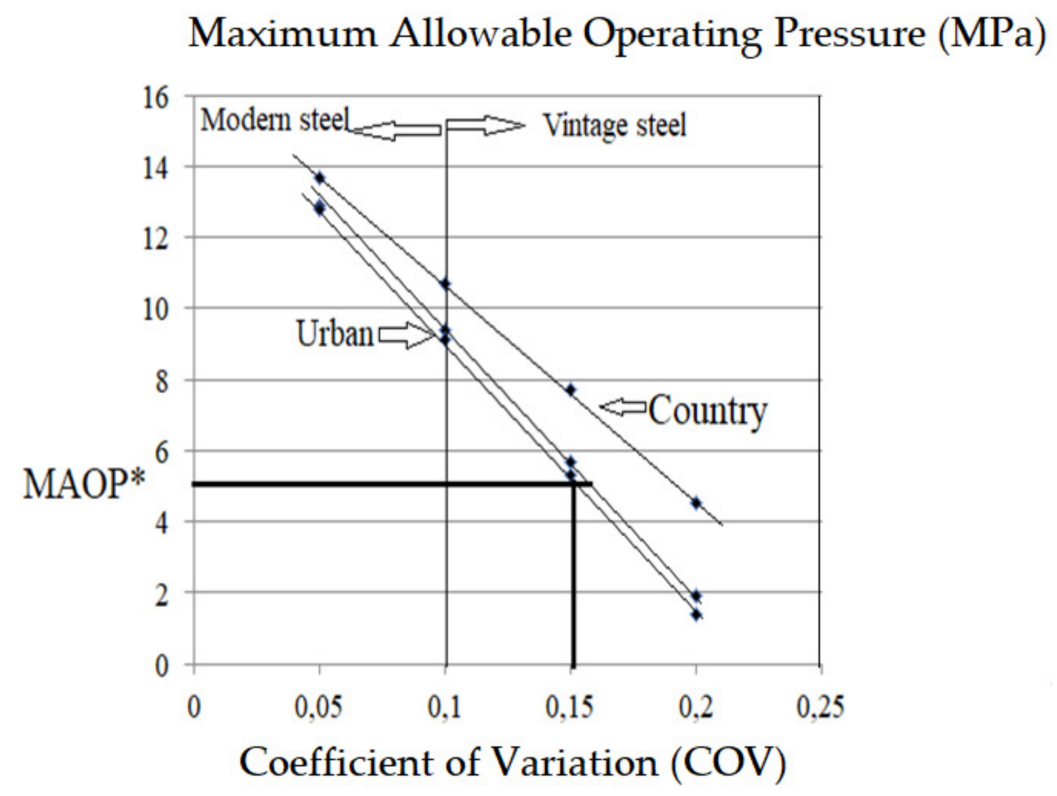

Figure 11. Influence of yield stress COV on MAOP according to locations for modern and vintage steels.

If we assume that that the economical threshold for MAOP, called MAOP* is $50 \mathrm{MPa}$, one cannot tolerate in the pipe networks, some part with vintage steels exhibiting a COV greater than 0.15 , see Figure 11.

\section{Maintenance of Cracked Pipe}

Very long pipes are made by in situ welding. Defects such as porosities, slag inclusions, melts or cracks are often present in the weld or the heat-affected zone (HAZ). Cracks have an irregular shape and are considered the most severe defects. For conservative reasons, they are considered elliptical or semi-elliptical surface cracks. By enclosing the irregular crack in a rectangle of length $2 \mathrm{c}$ and width $2 \mathrm{a}$ for internal cracks and length $(2 \mathrm{c})$ and depth (a) for surface cracks, one gets the equivalent crack geometry. The applied stress intensity factor of a semi-elliptic crack $K_{a p}$ is calculated according to the Newmann-Raju solution [19] valid for surface or internal cracks.

\subsection{Failure Assessment Diagram}

A plane representation of failure criterion is given by the Failure Assessment Diagram (FAD) methodology. FAD is a two-parameter fracture criterion where the non-dimensional crack driving force is plotted versus non-dimensional applied stress. The non-dimensional applied crack driving force is defined as the ratio of applied stress intensity factor $K_{a p}$ and the fracture toughness of the material $K_{I c}$.

$$
k_{r}^{*}=K_{a p} / K_{I c}
$$

The non-dimensional crack driving force is also defined from J integral or crack opening displacement:

$$
k_{r}^{*}=\sqrt{J_{a p} / J_{\text {mat }}} \text { or } k_{r}=\sqrt{\delta_{a p} / \delta_{\text {mat }}}
$$

where $\delta_{a p}, J_{a p}$ are the applied crack opening displacement and J integral. $\delta_{\text {mat }}$ or $J_{m a t}$ are fracture toughness in terms of material critical crack opening displacement or critical J Integral. The ratio of the gross stress and flow stress $\left(L_{r}=\sigma_{g} / \sigma_{0}\right)$ defines the non- 
dimensional stress. The flow stress is chosen as yield stress $\sigma_{Y}$, ultimate strength $\sigma_{u l}$ or classic flow stress $\sigma_{0}=\left(\sigma_{y}+\sigma_{u l}\right) / 2$.

Failure conditions (brittle, elastoplastic or, plastic collapse) are represented by an assessment point with coordinates $L_{r}^{*}, k_{r}^{*}$ in FAD. The failure curve fits all values of $\mathrm{k}_{\mathrm{r}, \mathrm{c}}$ and $\mathrm{L}_{\mathrm{r}, \mathrm{c}}$, Figure 12.

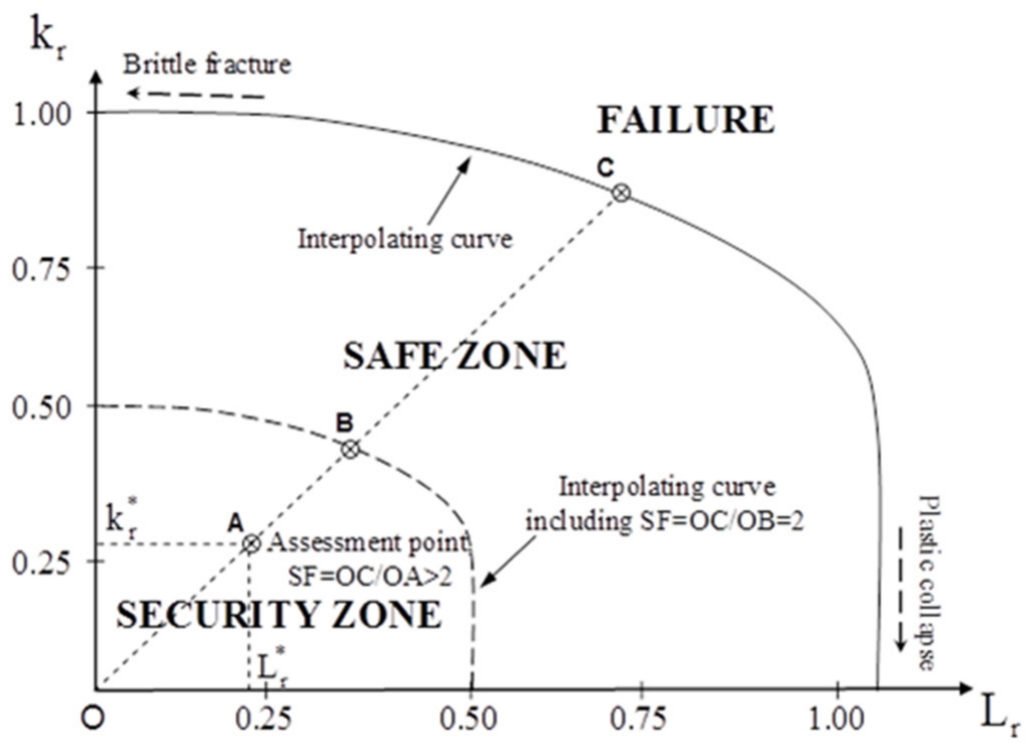

Figure 12. Failure Assessment Diagram (FAD).

The fracture design curve is the failure curve $\mathrm{k}_{\mathrm{r}, \mathrm{c}}=\mathrm{f}\left(\mathrm{L}_{\mathrm{r}, \mathrm{c}}\right)$ obtained according to the available codes, e.g., SINTAP [20], R6 [21] and RCC-MR [22].

Linearity of the loading path OC until critical load $P_{c}$ because $L_{r}$ and $k_{r}$ are proportional to load. A defect located in a pipe and loaded under service conditions is represented by an assessment point $\mathrm{B}$ (coordinates $\mathrm{Lr}_{\mathrm{r}}{ }^{*}$ and $\mathrm{k}_{\mathrm{r}}{ }^{*}$ ). A safe zone is the zone where no failure occurs, and the assessment point is inside. Assessment point on the assessment curves or above leads to critical conditions. The following relationship defines the deterministic safety factor:

$$
\mathrm{f}_{\mathrm{s}}=\mathrm{OC} / \mathrm{OB}
$$

By comparing the obtained safety factor to the conventional value of $\mathrm{f}_{\mathrm{s}}=2$, one gets an idea of the criticality of the situation.

The non-dimensional crack driving force is a direct function of the fracture toughness of the material. It decreases after HE for steels. In the yield stress range [350-600 MPa], fracture toughness decreases by $33 \%$. Increasing hydrogen pressure increases fracture toughness reduction. Figure 13 presents the variation of the assessment point with the same pipe loading conditions, for 10 pipe steels submitted to HE. The results concern tests under a gas pressure of 6.9 MPa. 
Non-dimensional Crack driving force

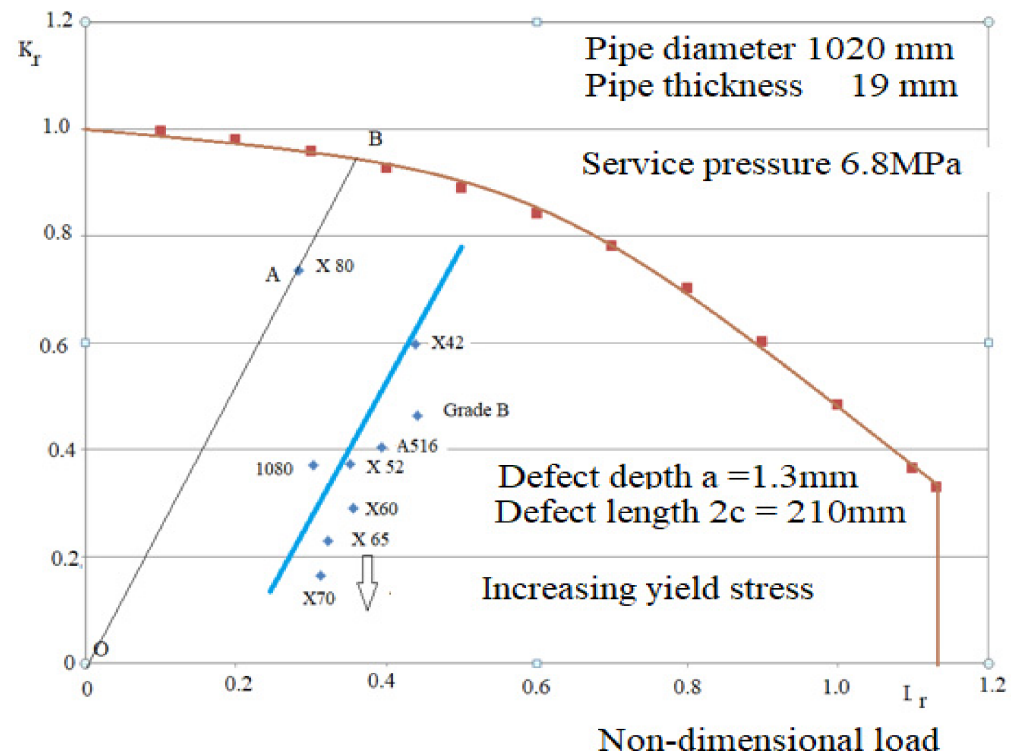

Figure 13. Assessment points of a semi-elliptical surface crack (depth $1.3 \mathrm{~mm}$, length $210 \mathrm{~mm}$ ) for 10 pipe steels submitted to hydrogen embrittlement.

\subsection{Influence of Hydrogen on the Loading Path in FAD}

Reduction in fracture toughness by hydrogen embrittlement HE decreases with the non-dimensional crack driving force $\mathrm{k}_{\mathrm{r}}$. Flow stress is not very affected by HE; therefore, it has practically no effect on non-dimensional load parameter.

A pipe subjected to internal pressure has a diameter $\mathrm{D}=611 \mathrm{~mm}$ and thickness $\mathrm{t}=11 \mathrm{~mm}$. The pipe is damaged with an internal semi-elliptical crack. Crack characteristics are depth over thickness ratio $\mathrm{a} / \mathrm{t}=0.5$ and aspect ratio $\mathrm{a} / \mathrm{c}=0.5$. Figure 14 shows that the loading path under $\mathrm{HE}$ is above the loading path without $\mathrm{HE}$. After $\mathrm{HE}$, the safety factor $\mathrm{f}_{\mathrm{s}}$ is modified.

\section{Non-dimensional crack driving force}

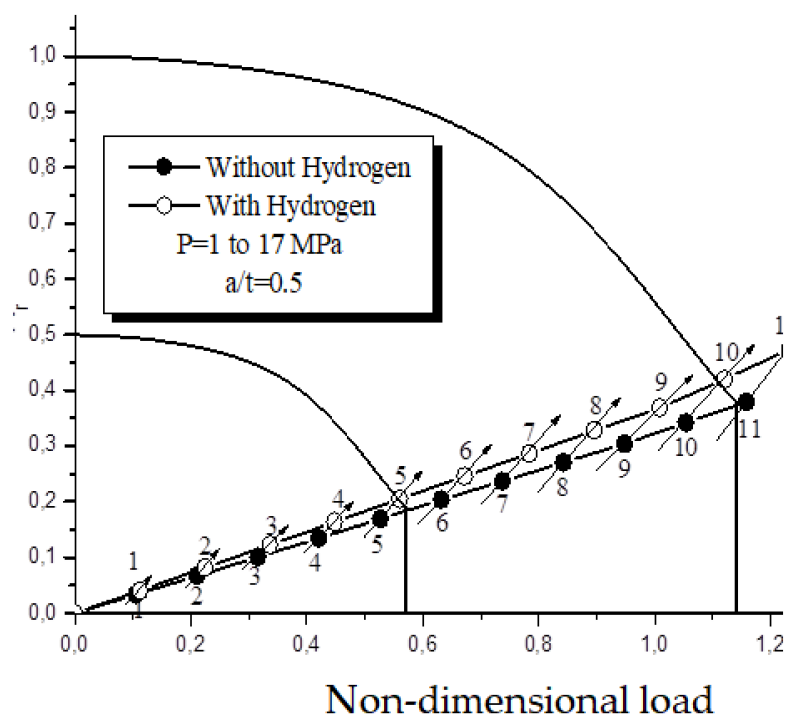

Figure 14. Two loading paths with and without HE; API 5L X52 steel, internal pressures: 1 and $17 \mathrm{MPa}$. Pipe diameter $\mathrm{D}=611 \mathrm{~mm}$ and thickness $\mathrm{t}=11 \mathrm{~mm}$, relative defect depth $\mathrm{a} / \mathrm{t} / 0.5$. 


\subsection{Influence of Hydrogen on the Safety Factor in FAD}

According to Equation (13), safety factors have been computed. The studied pipe is submitted to internal pressure $(p=5$ and $p=11 \mathrm{MPa})$. Five different values $(\mathrm{a} / \mathrm{t}=0.1,0.2$, $0.3,0.4$ and 0.5 ) of semi-elliptical defect sizes with identical aspect ratio is a/c $=0.5$ are considered. When the defect becomes deeper, the safety factor decreases. Failure occurs only for the highest pressure $(p=11 \mathrm{MPa})$ and for the deepest deep defects $(\mathrm{a} / \mathrm{t}=0.5$ without $\mathrm{HE}$ and $\mathrm{a} / \mathrm{t}=0.4$ with HE), see Table 6 .

Table 6. Safety factor $\left(f_{S}\right)$ values for different relative crack depth ratios (a/t $=0.1$ to 0.5$)$, with and without $\mathrm{HE}$ and for 2 different gas pressures ( $p=5 \mathrm{MPa}$ and $11 \mathrm{MPa})$.

\begin{tabular}{|c|c|c|c|c|c|c|}
\hline \multirow{3}{*}{$a / t$} & \multicolumn{3}{|c|}{$p=5 \mathrm{MPa}$} & \multicolumn{3}{|c|}{$p=11 \mathrm{MPa}$} \\
\hline & \multicolumn{2}{|c|}{$f_{s}$} & \multirow{2}{*}{ Diff. (\%) } & \multicolumn{2}{|c|}{$f_{s}$} & \multirow{2}{*}{ Diff. (\%) } \\
\hline & Without $\mathrm{H}_{2}$ & With $\mathrm{H}_{2}$ & & Without $\mathrm{H}_{2}$ & With $\mathrm{H}_{2}$ & \\
\hline 0.1 & 3.85 & 3.70 & 3.85 & 1.79 & 1.64 & 8.93 \\
\hline 0.2 & 3.45 & $1 / 0.32$ & 10.34 & 1.56 & 1.41 & 10.93 \\
\hline 0.3 & 3.03 & 2.63 & 15.15 & 1.37 & 1.20 & 13.70 \\
\hline 0.4 & 2.63 & 2.22 & 18.42 & 1.18 & Failure & \\
\hline 0.5 & 2.17 & 1.89 & 15.21 & Failure & Failure & \\
\hline
\end{tabular}

\section{Corrosion Defect Harmfulness after HE}

A corrosion defect considered as semi-elliptical has the following dimensions: depth (a), length (2c) and, width (W). Failure emanating from this defect is controlled by its size and the flow stress of the material. Pipe outer diameter (D), wall thickness $(t)$, specified minimum yield strength $\sigma_{\mathrm{y}, \mathrm{spc}}$ ), the longitudinal extent of corrosion (2c) and, defect depth (d) are input parameters to compute the Maximum allowable Operating Pressure (MAOP). Limit pressure solutions for pipe with corrosion defects are proposed in codes and the literature (ASME B31G [23], modified ASME B31G [24], DNV RP-F101 [25] and Choi et al. [26]). The limit pressure $P_{L}\left(p_{1}<P_{c}\right.$ the burst pressure) is expressed as:

$$
p_{L=\frac{2 t}{D} \cdot \sigma_{0}} \cdot\left[\frac{1-\alpha\left(\frac{a}{t}\right)}{1-\alpha\left(\frac{a}{t}\right) \cdot \frac{1}{M}}\right]
$$

Flow stress $\sigma_{0}, \alpha$ parameter and, Folias correction $M$ are different according to the applied method (see Table 7).

Table 7. Summary of limit pressure equations.

\begin{tabular}{cccc}
\hline Method & $\sigma_{\mathbf{0}}(\mathbf{M P a})$ & $\alpha$ & Folias Correction $\mathbf{M}$ \\
\hline B31G & $1.1 \sigma_{\mathrm{y}}$ & $2 / 3$ & - \\
\hline B31G & $1.1 \sigma_{\mathrm{y}}$ & 1.0 & $\infty$ \\
\hline Modified B31G & $\sigma_{\mathrm{y}}+69 \mathrm{MPa}$ & 0.85 & - \\
\hline Modified B31G & $\sigma_{\mathrm{y}}+69 \mathrm{MPa}$ & 0.85 & - \\
\hline DNV-RP-F101 & $\sigma_{\mathrm{ul}}$ & 1.0 & - \\
\hline API RP-579 & $\sigma_{\mathrm{y} / 0.9}$ & 1.0 & \\
\hline
\end{tabular}

Using ASME B31G as defect assessment method allows calculating the safe operating pressure associated as the limit pressure. The ratio of the Maximum Allowable Operating Pressure (MAOP) and the safe operating pressure $\mathrm{P}_{\text {safe }}$ is the estimated repair factor ERF. The following criterion for repairing is:

$$
\mathrm{ERF}=\frac{\mathrm{MAOP}}{\mathrm{p}_{\text {safe }}} \leq 1 \text { or } 0.95
$$


Repairing or lowering MAOP is required if the ERF greater than one. The defect assessment point $\left(2 c^{*} ; a^{*} / t\right)$ is reported in a graph of coordinates defect length, relative defect depth $(2 c ; a / t)$, Figure 15. The condition ERF $=1$ is reported in this graph as a curve.

\section{Relative depth a/t \%}

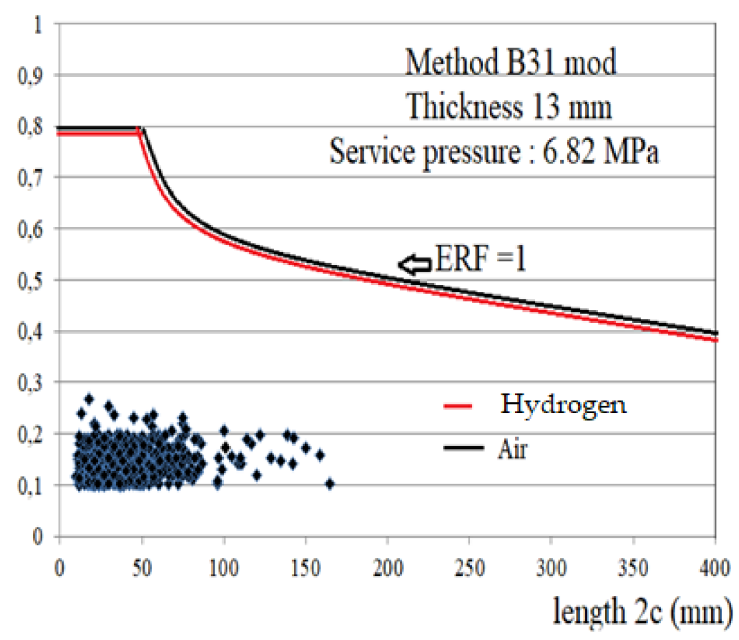

Figure 15. Relative defect depth versus defect length. Condition of repairing based on Estimated repair factor ERF.

A defect is acceptable if its assessment point is below the ERF assessment curve. The assessment point above this curve requires repair or service pressure de-rating. An ERF assessment curve is specific to each method (B31 or B31 mod) through the computing of $\mathrm{p}_{\text {safe }}$ or $p_{L}$. These parameters depend on pipe diameter, thickness, and material flow stress $\sigma_{0}$.

The linear loading path and the non-dimensional load axis are rotating from one angle called the assessment angle $\theta$. Two values of the assessment angle can be defined $\theta$. Two assessment angles determine three failure domains in the Domain Failure Assessment diagram (DFAD) diagram (Figure 16):

(i.) If $\theta<\theta_{1}$, it is localized the brittle fracture;

(ii.) If $\theta_{1}<\theta<\theta_{2}$, an elastoplastic fracture zone appears;

(iii.) If $\theta>\theta_{2}$, the plastic collapses.

According to Federsen [27], these zones are defined conventionally as follows:

$$
\begin{gathered}
\text { Zone I: } 0<\mathrm{L}_{\mathrm{r}} \leq 0.62 \mathrm{~L}_{\mathrm{r}, \mathrm{y}} \\
\text { Zone II: } 0.62 \mathrm{~L}_{\mathrm{r}, \mathrm{y}}<\mathrm{L}_{\mathrm{r}} \leq \mathrm{L}_{\mathrm{rmax}} \\
\text { Zone III: } \mathrm{L}_{\mathrm{r}}>\mathrm{Lr}_{\text {, } \max }
\end{gathered}
$$

where $L_{r, y}$ is the non-dimensional yield pressure and $L_{r, m a x}$ is a cut-off value. NFAD, Figure 16, is used to choose the assessment method for failure risk evaluation for a pipe with a defect. For the pipe steel, $\mathrm{L}_{\mathrm{r}, \max }=1.079$.

A pipe made from API 5L X52 steel with a corrosion defect is submitted to internal pressure. The pipe diameter is $\mathrm{D}=611 \mathrm{~mm}$ and the thickness $\mathrm{t}=11 \mathrm{~mm} \mathrm{t}$. This corrosion defect is considering as equivalent to an internal semi-elliptical crack (aspect ratio a/c $=0.5$ and relative crack depth $\mathrm{a} / \mathrm{t}=0.5$ ). Applied $\mathrm{J}$ integral is computed with the true stress/strain with and without HE of API 5L X52 pipeline steel. 


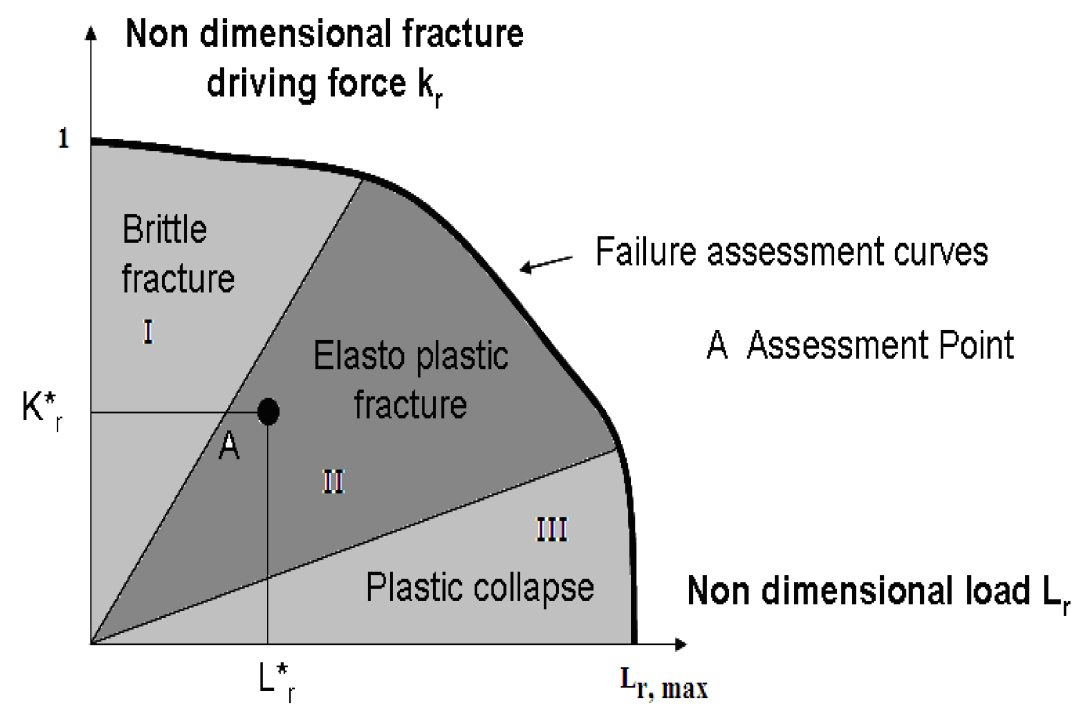

Figure 16. Domain failure assessment diagram.

From this applied J Integral $\mathrm{J}_{\mathrm{ap}}$, the non/dimensional crack driving force is defined as:

$$
\mathrm{k}_{\mathrm{r}}^{*}=\sqrt{\mathrm{J}_{\mathrm{ap}} / \mathrm{J}_{\mathrm{mat}}}
$$

where $\mathrm{J}_{\mathrm{mat}}$ is the material fracture toughness. The loading path is presented in Figure 17 (with and without HE).

Non-dimensional crack driving force

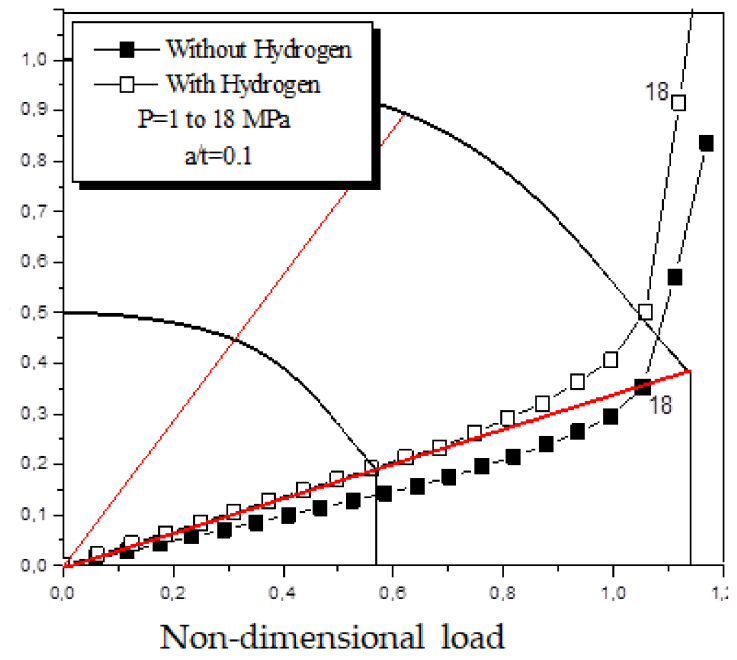

Figure 17. Loading path under or without HE. Pipe diameter $\mathrm{D}=611 \mathrm{~mm}$ and thickness $\mathrm{t}=11 \mathrm{~mm}$, relative defect depth $\mathrm{a} / \mathrm{t}=0.1$. Pipe from API 5L X52 steel and submitted to internal pressure $p$.

The defect assessment (for a relative crack depth $a / t=0.1$ ) is situated in the limit analysis domain when the material is not submitted to, HE. When submitted, the assessment point is situated in the LEFM domain.

In the LEFM domain, the safety factor is given by:

$$
\mathrm{f}_{\mathrm{S}, \mathrm{LEFM}}=\mathrm{OC} / \mathrm{OB}
$$

The safety factor for the limit analysis domain is defined as: 


$$
\mathrm{f}_{\mathrm{s}, \mathrm{LA}}=p_{s} / \mathrm{p}_{l}
$$

where $\mathrm{p}_{l}$ the limit pressure (according to ASME B31 [23]) and $p_{s}$ is the service pressure. In Table 8 , values of the safety factor for different relative defect depth ratios $(a / t=0.1$ to 0.5 ), two different gas pressures as well hydrogen embrittlement are reported. $\mathrm{F}_{\mathrm{s}, \mathrm{LA}}$ is calculated when the loading path is situated in the LA domain, i.e., for the relative defect depth $a / t=0.1 ; 0.2$ and 0.3 . The safety factors decrease when the applied pressure increases. HE induces a decrease in $\mathrm{f}_{\mathrm{s}}$ by less than $10 \%$. The safety factor associated with LA is always greater than the LEFM one. It decreases when the relative defect depth increases.

Table 8. Safety factor $\left(f_{s}\right)$ values for different relative crack depth ratios (a/t $=0.1$ to 0.5$)$, with and without hydrogen and for different gas pressures $(p=5 \mathrm{MPa}$ and $11 \mathrm{MPa})$.

\begin{tabular}{ccccccc}
\hline $\mathbf{f}_{\mathbf{s}}$ & \multicolumn{3}{c}{$\mathbf{p}_{\mathbf{a p}}=\mathbf{5}$ MPa } & \multicolumn{3}{c}{ pap $=11 \mathrm{MPa}$} \\
\hline $\mathbf{a} / \mathbf{t}$ & $\begin{array}{c}\text { without HE } \\
\text { (EPFM) }\end{array}$ & $\begin{array}{c}\text { without HE } \\
\text { (LA) }\end{array}$ & $\begin{array}{c}\text { with HE } \\
\text { (EPFM) }\end{array}$ & $\begin{array}{c}\text { without HE } \\
\text { (EPFM) }\end{array}$ & $\begin{array}{c}\text { without } \\
\text { HE (LA) }\end{array}$ & $\begin{array}{c}\text { with HE } \\
\text { (EPFM) }\end{array}$ \\
\hline 0.1 & - & 3.47 & 3.70 & - & 1.58 & 1.67 \\
\hline 0.2 & - & 3.47 & 3.23 & - & 1.58 & 1.47 \\
\hline 0.3 & - & 3.47 & 2.78 & - & 1.58 & 1.27 \\
\hline 0.4 & 2.63 & - & 2.33 & 1.18 & - & 1.04 \\
\hline 0.5 & 2.17 & - & 2.00 & 0.98 & - & 0.89 \\
\hline
\end{tabular}

\section{Strain-Based Design}

Where loadings of pipelines are due to forces other than the internal pressure, strainbased design (SBD) is used. In this case, large stresses and strains in the pipe wall are produced.

When stresses and strains exceed the proportional limit SBD is rather used [28,29]. Stress-based methods are ruled by material stress-strain behavior. The strain-based design avoids these problems when strain and stress are not proportional. SBD is associated with limit states. Several limit states are considered with SBD: failure in tension (material limit state) and buckling by compression (material and serviceability limit states).

SBD fundamental equation is based on a comparison of the strain demand $\varepsilon_{d}$ and critical strain $\varepsilon_{\mathrm{c}}$

$$
\varepsilon_{d} \leq \varepsilon_{c}
$$

In the absence of additional engineering information, a maximum strain limit of $10 \%$ $(0.1)$ is considered. The safety factor $\mathrm{f}_{\mathrm{S}}$ defines the critical strain capacity $\varepsilon_{\mathcal{c}}$ :

$$
\varepsilon_{c}=\frac{\varepsilon_{l}}{f_{s}}
$$

where $\varepsilon_{l}$ is the limit strain. Safety factors according to the safety classes for tension are given in Table 9. They are different for compression buckling. The difference between stress-based design and SBD is given in Figure 18. The strain-based design of pipelines is described in several codes. DNV 2000 [28] and CSA Z662 [29] include requirements both for stress- and strain-based design. B31.8 [30] and API 1104 [31] incorporate strain-based design. API RP 1111 [32] provides information on SBD related to a specific type of pipeline.

Table 9. Safety classes for tension and associated safety factors.

\begin{tabular}{cccc}
\hline Tension Strain Safety Factor & & Class \\
\hline \multirow{2}{*}{ safety class } & Low & normal & high \\
\cline { 2 - 4 } & 1.5 & 2 & 3 \\
\hline
\end{tabular}



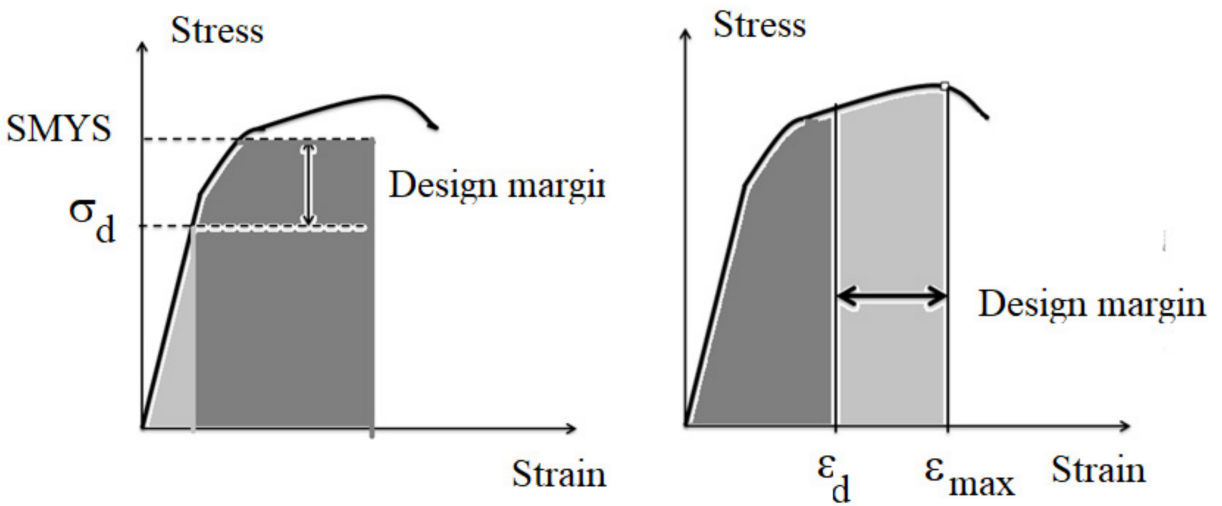

Figure 18. Principle of stress- and strain-based designs (SDB). (SMYS, standard minimum yield strength; $\sigma_{\mathrm{d}}$, stress demand; $\varepsilon_{\mathrm{d}}$, strain demand; and $\varepsilon_{\max }$, strain capacity).

\subsection{Influence of Loading Mode}

The failure strain is sensitive to hydrostatic pressure $\sigma_{\mathrm{m}}$ and the Lode Angle, $\theta_{L}$. These parameters are considered in the Wierzbicki and Xue model [33]. Failure strain is governed by the product of two specific functions associated with each parameter.

$$
\varepsilon_{f}\left(\sigma_{h}, \theta_{L}\right)=\epsilon_{f, 0} * \mu_{\sigma_{h}}\left(\sigma_{h}\right) * \mu_{\theta_{L}}\left(\theta_{L}\right)
$$

$\epsilon_{f, 0}$ is the reference failure strain. The dependence with hydrostatic pressure $\sigma_{h}$ is given by:

$$
\mu_{\sigma_{h}}\left(\sigma_{h}\right)=1-q \log \left(1-\frac{\sigma_{h}}{\sigma_{h}, l}\right)
$$

if

$$
\begin{aligned}
& \sigma_{h} \geq \sigma_{h, l} \cdot\left[1-\exp \left(\frac{1}{q}\right)\right] \\
& \mu_{\sigma_{h}}\left(\sigma_{h}\right)=0
\end{aligned}
$$

if

$$
\sigma_{h}<\sigma_{h, l} \cdot\left[1-\exp \left(\frac{1}{q}\right)\right]
$$

$q$ a material parameter. $\sigma_{h, l}$ is the hydrostatic limit pressure. The dependence with the Lode angle is a power function as:

$$
\mu_{\theta_{L}}\left(\theta_{L}\right)=\gamma+(1-\gamma) \cdot\left(\frac{6\left|\theta_{L}\right|}{\pi}\right)^{k}
$$

Dependence with Lode angle $\mu_{\theta_{L}}\left(\theta_{L}\right)$ is presented in polar coordinates.

$$
\begin{gathered}
\mu_{\theta_{L}}\left(\theta_{L}\right)=\frac{r_{0}}{\cos \left(\theta_{L}-\theta_{0}\right)} \\
r_{0}=\frac{\gamma}{2 \sqrt{\gamma^{2}-\sqrt{3} \gamma+1}} \\
\theta_{0}=\cos ^{-1} \frac{\gamma}{2 \sqrt{\gamma^{2}-\sqrt{3} \gamma+1}}
\end{gathered}
$$

$\gamma$ is a material parameter. By increasing the values of $\gamma$, one increases the influence of shear conditions on failure strain. 


\subsection{Influence of Hydrogen on Failure Elongation}

Figure 19 shows for several pipe steels, the ratio of failure elongation under $\mathrm{HE}$ and without. One notes that the failure elongation ratio of $\mathrm{A} \%(\mathrm{H} 2) / \mathrm{A} \%$ (air) decreases when the steel yield stress increases, however the scatter.

\section{Failure elongation ratio (H2/air)}

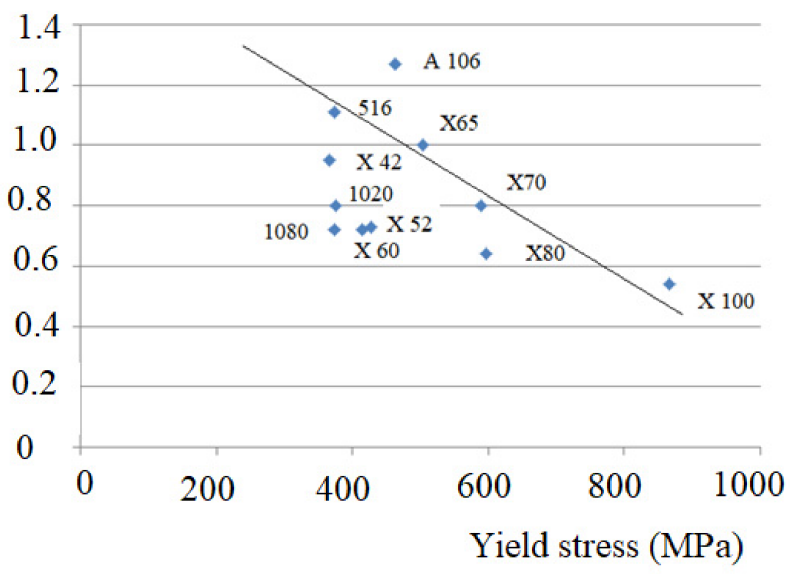

Figure 19. Ratio of failure elongation $\left(\mathrm{H}^{2} /\right.$ air $)$ ratio for several pipe steels.

\subsection{Application to Maximum Dent Depth after Hydrogen Embrittlement}

Figure 20 shows a plain dent. A plain dent modifies the curvature of the pipe wall without reduction in pipe thickness. The distance between undamaged and damaged cross-sections defines the dent depth $(H)$. Plain dents have no sharp defects such as a gouge and possess a smooth profile.

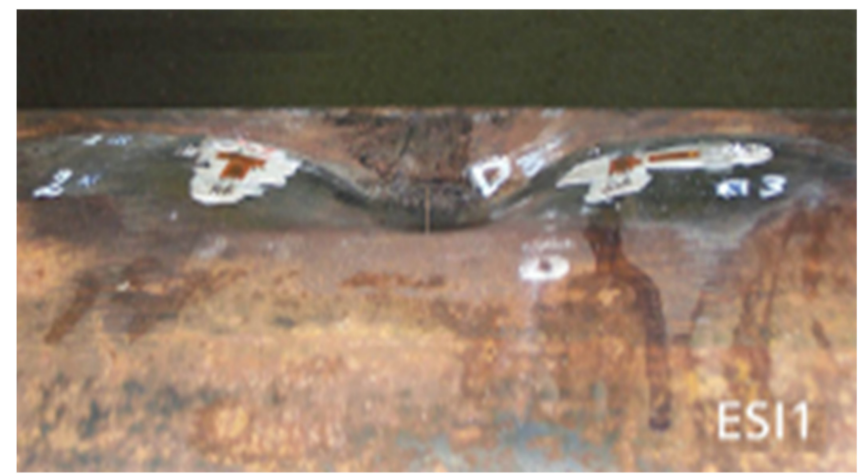

Figure 20. General aspect of a plain dent in a pipe.

For plain dents, it is necessary to consider the following parameters:

- Service pressure;

- Applied cyclic pressure range;

- Dent depth;

- Pipe geometry (ratio of diameter to wall thickness);

- Dent profile curvature.

Depth is the most significant factor affecting the burst strength and the fatigue life of a plain dent. The acceptability limits of dent depth are generally given by empirical rules. Depths up to $8 \%$ of pipe diameter [34] do not significantly reduce the burst strength of a pipeline. The possibility of $24 \%$ [35] exists for a plain smooth dent. Therefore, when dent depth is more than one-tenth of the pipe diameter, repairing is mandatory. 
For the API 579 code [36], dents are dangerous if they occur on longitudinal weld seams where cracks can develop. The European Pipeline Research Group (EPRG) [37] indicates that dent depths up to $10 \%$ of the pipe outside diameter will not fail at membrane stress levels below $72 \%$ of the SMYS:

$$
\frac{H}{D_{e}} \leq 10 \%
$$

where $H=$ dent depth in the non-pressurized condition in $(\mathrm{mm})$ and $D_{e}=$ pipe outside diameter $(\mathrm{mm})$. The reduction in the dent depth by internal pressure (spring-back phenomenon) pushes out the dent. The measured depth must be corrected. EPRG found a correlation between the dent depth on a non-pressurized pipe and a pressurized pipe to be as follows [37]:

$$
\mathrm{H}=1.43 \mathrm{H}_{0}
$$

where $\mathrm{H}_{0}$ is the depth of the dent in the non-pressurized condition in (mm). According to EPRG, the dent depth limit in a pressurized pipe is [37]:

$$
\frac{H_{0}}{D_{e}} \leq 7 \%
$$

A local strain criterion can be used to assess a dent This criterion assumes that the maximum local stress $\varepsilon_{l, c}$ has to be less than the failure strain $\varepsilon_{\mathrm{f}}$

$$
\varepsilon_{l, c}=\varepsilon_{f}
$$

The Oyane et al. criterion [38] is a local ductile failure criterion and written as follows:

$$
I=\frac{1}{C_{2}} \int_{0}^{\overline{\varepsilon_{f}}}\left(C_{1}+\frac{\sigma_{h}}{\bar{\sigma}}\right) d \bar{\varepsilon}
$$

where $\overline{\varepsilon_{f}}$ is the equivalent failure strain; $\sigma_{h}$ the hydrostatic stress $\bar{\sigma}$ the equivalent stress; $\bar{\varepsilon}$ the equivalent deformation; $C_{1}$ and $C_{2}$ are material constants.

Oyane's criterion is calculated for different dent depths. An example is given in Figure 21 for a pipe made in API 5L X52 steel (failure elongation is $31.5 \%$ and after HE $23 \%$ ). The results of calculations of I integral are related to material damage. One notes that this damage is much more severe when the steel is subjected to HE. After HE, the maximum damage is reached for a ratio $\mathrm{H}_{0} / \mathrm{D}_{\mathrm{e}}=4 \%$.

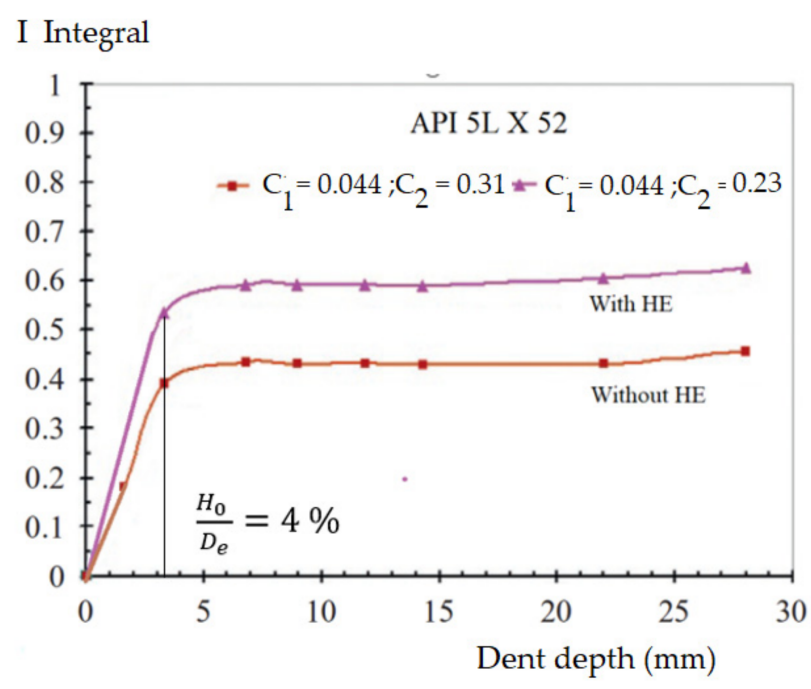

Figure 21. Integral I obtained by Finite element computation (Oyane's criterion) versus dent depth. 


\section{Conclusions}

For transport of pure hydrogen or blended with natural gas, pipe design needs to consider the damage of pipe steels by hydrogen embrittlement.

The transition temperature is relatively low when compared with service temperature but are few affected by HE. Therefore, the reference temperature does not need to be modified.

The Maximum Admissible Operating Pressure (MAOP) needs to be modified through the design factor however the yield stress is few affected by HE. Therefore, the risk to human life is increased by the low ignition energy and large inflammability range of hydrogen.

HE strongly affects elongation at failure. Where loadings of the pipelines are due to forces other than the internal pressure, strain-based design (SBD) is used. This ensures that the strain demand remains less than strain capacity. These problems are partially covered in codes such as the ones in [9].

Specific tools are necessary for pipe defect assessment (FAD, NFAD, ERF and damage criteria). They are specific to defect type (crack, gouge, corrosion crater or dent). These tools incorporate specific materials properties such as yield stress (low sensitivity to HE), fracture toughness, or failure elongation (very sensitive to HE). FAD, NFAD, ERF and damage criteris are recommended for a better defect assessment in pipes.

Author Contributions: Conceptualization, P.G., T.L.; methodology, C.J.; software, C.J; validation, P.G., T.L. and C.J.; formal analysis, P.G., T.L. and C.J.; writing-original draft preparation, P.G. and T.L.; writing - review and editing, P.G. and T.L. All authors have read and agreed to the published version of the manuscript.

Funding: This research received no external funding.

Institutional Review Board Statement: Not applicable.

Informed Consent Statement: Not applicable.

Data Availability Statement: No reported data.

Conflicts of Interest: The authors declare no conflict of interest.

\section{References}

1. Abe, J.O.; Popoola, A.P.I.; Ajenifuja, E.; Popoola, O.M. Hydrogen energy, economy and storage: Review and recommendation. Int. J. Hydrogen Energy 2019, 44, 15072-15086. [CrossRef]

2. Berry, G.D.; Pasternak, A.D.; Rambach, G.D.; Smith, J.R.; Schock, R.N. Hydrogen as a future transportation fuel. Energy 1996, 21, 289-303. [CrossRef]

3. Vries, H.; Mokhov, A.V.; Levinsky, H.B. The impact of natural gas/hydrogen mixtures on the performance of end-use equipment: Interchangeability analysis for domestic appliances. Appl. Energy 2017, 208, 1007-1019. [CrossRef]

4. Available online: https://innovation.engie.com/en/news/news/new-energies/the-grhyd-project-converting-renewableelectric-power-into-gas-1/53 (accessed on 7 April 2018).

5. Florisson, O. Preparing for the Hydrogen Economy by Using the Existing Natural Gas System as a Catalyst. Natural Hy Project Report SES6/CT/2004/502661. 2010. Available online: http://www.naturalhy.net/docs/project_reports/Final_Publishable_ Activity_Report.pdf (accessed on 23 October 2020).

6. Johnson, W.H. On some remarkable changes produced in iron and steel by the action of hydrogen and acids. Proc. R. Soc. Lond. 1875, 23, 168-179. [CrossRef]

7. Pluvinage, G.; Capelle, J.; Meliani, M.H. Pipe networks transporting hydrogen pure or blended with natural gas, design and maintenance. Eng. Fail. Anal. 2019, 106, 104164. [CrossRef]

8. Steigerwald, E.A.; Schaller, F.W.; Troiano, A.R. The role of stress in hydrogen induced delayed failure. Trans. Metall. Soc. AIME 1960, 218, 832 .

9. Magnin, T. Mécanismes de fatigue-corrosion des alliages métalliques. La Revue de Métallurgie-CIT/Science et Génie des Matériaux, Mai. Rev. Met. Paris 2002, 99, 423-432.

10. Capelle, J.; Gilgert, J.; Pluvinage, G. Hydrogen effect on fatigue life of a pipe steel. In Safety, Reliability and Risks Associated with Water, Oil, and Gas Pipelines; Pluvinage, G., Elwany, M., Eds.; Springer: Berlin/Heidelberg, Germany, 2007; pp. $205-2218$.

11. Capelle, J.; Gilgert, J.; Pluvinage, G. A fatigue initiation parameter for gas pipe steel submitted to hydrogen absorption. Int. J. Hydrogen Energy 2010, 35, 833-843. [CrossRef] 
12. Dadfarnia, M.; Sofronis, P. Assessment of Resistance of Line Pipe Steels to Hydrogen Embrittlement Report of University of Illinois; University of Illinois: Urbana, IL, USA, 29 November 2016.

13. Fitness-For-Service. API 579-1/ASME FFS-1; American Petroleum Institute: Washington, DC, USA; The American Society of Mechanical Engineers: New York, NY, USA, 2017.

14. Coseru, A.; Capelle, J.; Pluvinage, G. On the use of Charpy transition temperature as reference temperature for the choice of a pipe steel. Eng. Fail. Anal. 2014, 37, 110-119. [CrossRef]

15. Oldfield, W. Development of fracture toughness reference curves. J. Eng. Mater. Technol. 1980, 102, 107-117. [CrossRef]

16. Fassina, P.; Bolzoni, F.; Fumagalli, G.; Lazzari, L.; Vergani, L.; Sciuccati, A. Influence of hydrogen and low temperature on mechanical behaviour of two pipeline steels. Eng. Fract. Mech. 2012, 81, 43-55. [CrossRef]

17. American Society of Mechanical Engineers. Hydrogen Piping and Pipelines; American Society of Mechanical Engineers: New York, NY, USA, 2015.

18. Kuk Mijim, J.; Pluvinage, G.; Capelle, J.; Azari, Z.; Benamara, M. Probabilistic design factors for pipes used for hydrogen transport. Int. J. Hydrogen Energy 2020, 45, 33860-33870. [CrossRef]

19. Newman, J.C.; Raju, I.S. Stress intensity factor for internal and external surface cracks in cylindrical pressure vessels. J Press. Vessel Technol. 1982, 104, 293-298.

20. SINTAP: Structural Integrity Assessment Procedure; Final Report E-U Project BE95-1462 Brite Euram Programme; Publications Office of the EU: Brussels, Belgium, 1999.

21. Harrisson, R.P.; Milne, I.; Loosmore, K. Assessment of the Integrity of Structures Containing Defects; Report R/H R6 Revision 1; Central Electricity Generating Board: Leatherhzead, Surrey, UK, 1977.

22. RCC-MRx 2015-EN Design and Construction Rules for Mechanical Components of Nuclear Installations: High-Temperature, Research and Fusion Reactors; AFCEN: Paris, France, 2015.

23. ASME B31G-1991. Manual for Determining the Remaining Strength of Corroded Pipelines; The American Society of Mechanical Engineers: New York, NY, USA, 1991.

24. Kiefner, J.; Vieth, P. A modified criterion for evaluating the strength of corroded pipe. In Final Report for PR 3-805 Project to the Pipeline Supervisory Committee of the American Gas Association; Battelle: Columbus, OH, USA, 1989.

25. DNV-RP-F101 Recommended Practice; DNVRP-F101, Corroded Pipelines; Det Norske Veritas: Belum, Norway, 2004.

26. Choi, J.B.; Goo, B.K.; Kim, J.C.; Kim, Y.J.; Kim, W.S. Development of limit load solutions for corroded gas pipelines. Int. J. Press. Vessels Pip. 2003, 80, 121-128. [CrossRef]

27. Feddersen, C.E. Evaluation and Prediction of Residual Strength of Center Cracked Tension Panels; ASTM STP 486: 50-62; ASTM: New York, NY, USA, 1970.

28. DNV 2000, DNV-OS-F101 Submarine Pipeline Systems; det Norske Veritas: Belum, Norway, 2000.

29. CSA Z662 Oil and Gas Pipeline Systems; Canadian Standards Association: Mississauga, ON, Canada, 1999.

30. ASME B31.8. Gas Transmission and Distribution Piping Systems; American Society of Mechanical Engineers: New York, NY, USA, 2012.

31. API 1104. Welding of Pipelines and Related Facilities, 19th ed.; American Petroleum Institute: Washington, DC, USA, 1999.

32. API RP 1111. Design, Construction, Operation and Maintenance of Offshore Hydrocarbon Pipelines (Limit State Design); American Petroleum Institute: Washington, DC, USA, 1998.

33. Wierzbicki, T.; Xue, L. Ductile fracture initiation and propagation modelling using damage plasticity theory. Eng. Fract. Mech. 2008, 75, 3276-3293.

34. Eiber, R.J. The Effect of Dents on the Failure Characteristics of Linepipe; NG 18, Report N 125; Batelle Colombus Laboratories: Columbus, OH, USA, May 1981.

35. Jones, D.G. The Significance of Mechanical Damage in Pipelines. 3R Int. 1982, 21, 347-354.

36. Fitness-for-Service. API Recommended Practice 579, 1st ed.; American Petroleum Institute: Washington, DC, USA, January 2000.

37. Roovers, P.; Bood, R.; Galli, M.; Marewski, U.; Steiner, M.; Zarea, M. EPRG Methods for Assessing the Tolerance and Resistance of Pipelines to External Damage, Pipeline Technology, Volume II. In Proceedings of the Third International Pipeline Technology Conference, Brugge, Belgium, 21-24 May 2000; Denys, R., Ed.; Elsevier Science: Amsterdam, The Netherlands, $2000 ;$ pp. 405-425.

38. Oyane, M.; Sato, T.; Okimoto, K.; Shima, S. Criteria for ductile fracture and their application. J. Mech. Work Technol. 1980, 4, 65-81. [CrossRef] 